Max-Planck-Institut für demografische Forschung

Max Planck Institute for Demographic Research

Konrad-Zuse-Strasse 1 - D-18057 Rostock - GERMANY

Tel +49 (0) 3812081 - 0; Fax +49 (0) 3812081 - 202;

http://www.demogr.mpg.de

MPIDR WORKING PAPER WP 2012-027

SEPTEMBER 2012

\title{
Comprehensive Analyses of Fertility \\ Trends in the Russian Federation during the Past Half Century
}

\author{
Tomas Frejka \\ Sergei Zakharov
}

This working paper has been approved for release by: Vladimir Shkolnikov (shkolnikov@demogr.mpg.de), Head of the Laboratory of Demographic Data.

(C) Copyright is held by the authors.

Working papers of the Max Planck Institute for Demographic Research receive only limited review. Views or opinions expressed in working papers are attributable to the authors and do not necessarily reflect those of the Institute. 


\title{
Comprehensive Analyses of Fertility Trends in the Russian Federation during the Past Half Century
}

Tomas Frejka, Independent consultant

Sergei Zakharov, Institute of Demography, Higher School of Economics, Moscow

\begin{abstract}
The transformation of traditional childbearing patterns of early family formation to later family formation characterized recent fertility trends in Russia. These were intrinsically interwoven with fundamental changes in all aspects of life of young people in the 1990s and the 2000s. The past quarter century was also marked by concern with low fertility and attempts to increase fertility in the early 1980s and the late 2000s. The family policies of the 1980s failed to raise fertility. Preliminary analyses indicate that the fate of the 2007 policies could be similar. In both cases the main emphasis was on material birth and child benefits, parental leaves and child care. Presumably insufficient attention was devoted to improving living conditions of young people and promoting gender equality. Will government efforts to raise fertility during the 2010s be sufficiently effective to offset economic and social forces challenging childbearing? As of 2012 the outlook for a future fertility increase does not appear hopeful.
\end{abstract}




\section{Comprehensive Analyses of Fertility Trends in the Russian Federation during the Past Half Century}

Fertility trends in the Russian Federation of the past half century are analyzed in this paper. The analysis takes on an added significance because it covers the historical transition period when state socialism was being replaced by contemporary capitalism, and two waves of substantial pro-natalist policy measures were implemented, the first one in the early 1980s and the second one in 2007.

The first set of policy measures caused the total period fertility rate (TPFR) to increase by 20 percent between 1980 and 1987, from 1.86 to 2.23 births per woman. This was followed by a precipitous decline. By 1999 the TPFR reached a low of 1.16 (Figure 1). The rise in the TPFR during the 1980s was primarily generated by childbearing advancement. The total cohort fertility rate remained stable around 1.85 for the women born during the 1950s and subsequently declined among the 1960s cohorts. The fertility decline of the late 1980s and the 1990s was an inherent element of the ongoing major societal, economic and political, changes and coincided with the beginning of the childbearing postponement process during the early 1990s.

The second set of policy measures caused the period total fertility rate to increase by 21 percent between 2006 and 2010, from 1.30 to 1.57 births per woman. It is not yet possible to conduct a thorough analysis of the role of childbearing timing played in this increase. It is reasonable to assume that it did play an important role in the fertility increase. Preliminary estimates indicate that the TCFR is likely to stabilize around 1.6 births per woman among the 1970s and possibly also the 1980s birth cohorts. This would imply that the TPFR increase of the late 2000s was for the most part, possibly entirely, the result of childbearing advancement and that there was no increase in the quantum of fertility. Moreover, preliminary calculations indicate that the initial effectiveness of the 2007 pro-natalist measures was wearing off by 2010. In 2007 the TPFR increased by 0.11 births per woman in comparison to the previous year, a gain of 8.5 percent. The absolute increase in the TPFR between 2009 and 2010 was 0.03 births per woman, a 2.1 percent increment.

The specifics of the childbearing postponement and recuperation process in Russia are also discussed in this paper. It started with the mid 1960s birth cohorts apparently triggered by the societal, economic and political conditions of the late 1980s and early 1990s at the time when the effects of the 1980s pro-natalist measures were wearing off. The postponement process was proceeding at an even pace during the 1990s and was still in progress among the cohorts of the early 1980s around 2010.

The principal focus of this paper is on an analysis of fertility trends, however these were intrinsically interwoven with fundamental changes in essentially all aspects of life of young people. Under the communist system space for individual freedom was severely limited by official ideology and by parental paternalism, whereas starting in the late 1980s their aspirations to a higher material and social status were unleashed. The distinctive pattern of early marriage which in effect had prevailed since the $19^{\text {th }}$ century was undergoing rapid changes. The age of first marriage was rising and other forms of cohabitation were becoming increasingly adopted 
(Zakharov 2006). There was a substantial growth in levels of education. For instance, among women up to 25 years of age the share of those with higher education in the 1955-1964 cohort was 21 percent which increased to 33 percent in the 1975 to 1979 cohort (GGS 2007). A virtual contraceptive revolution was taking place with traditional methods being replaced by modern ones and leading to a rapid decline in induced abortions as well as unwanted births (Zakharov 2006). Women's empowerment was improving. Sexual behavior was changing as evidenced by a reduced age of sexual debut which did not have to be legitimized by marriage. All of these and other developments were mirrored also in fertility trends.

In the next section the data and methods applied in the paper are discussed. This is followed by a detailed demographic analysis of various aspects of cohort and fertility trends and patterns. The content and effectiveness of the 1980s and the 2007 policy measures are then analyzed. The paper concludes with a summary and conclusions.

\section{Data and Methods}

\section{Data}

The analysis is based on period and cohort fertility data for the Russian Federation assembled in the Human Fertility Database (HFD 2011) of the Max Planck Institute for Demographic Research in Rostock, Germany. As of October 2011, period age-specific fertility rates by single years of mother's age were available for the years 1959-2009. Age-specific cohort fertility data that could be used for analysis were available starting with the 1940 birth cohort. The 1958 birth cohort was the last one for which age-specific fertility rates were available for all ages 15-50, however, incomplete data up to the 1985 birth cohort were used in our analysis. In addition, period fertility data for the year 2010 were provided by the Institute of Demography of the Higher School of Economics in Moscow.

\section{Methods}

Most of the methods applied in the demographic analysis are those developed and described in Sobotka et al. (2011) "Postponement and Recuperation in Cohort Fertility: New analytical and projection methods and their application.” In principle, this consists of a thorough multi-faceted comparative analysis of age-specific, single-year and cumulative, cohort fertility rates by birth order. For part of the demographic analysis the method developed by Frejka (2011) examining how cohort and period childbearing postponement and recuperation (P\&R) are reflected in total period fertility rate trends in low-fertility populations in recent decades was applied.

In addition to the traditional measures, such as total period and cohort fertility rates, age-specific period and cohort fertility rates, and cumulated period and cohort fertility rates, some recently devised measures are used. The new indicators measure specific aspects of the postponement and recuperation process. The new measures are illustrated in Diagram 1. Postponement and recuperation are measured by age for any cohort of interest, labeled as $c$, which is compared with an older reference cohort (benchmark cohort, labeled as b). Usually, postponement is measured by cumulating absolute or relative fertility declines across all ages when fertility declined, while 
recuperation is measured by cumulating absolute or relative fertility increases across all ages when fertility increased relative to the reference cohort. This is illustrated using hypothetical cohorts $b$ and $c$ in Diagram 1. The new measures are:

- The absolute cumulative decline at young ages at trough (maximum age of decline): $\mathrm{P}_{\mathrm{c}}$ (= -0.59 in Diagram 1)

- The absolute recuperation between trough age and the end of reproductive life: $R_{c}(=$ +0.52 in Diagram 1)

- The Recuperation Index: $\mathrm{RI}_{\mathrm{c}}=\mathrm{R}_{\mathrm{c}} /\left(-\mathrm{P}_{\mathrm{c}}\right)$, which is the relative amount of recuperation (In our example $0.52 / 0.59=0.88$, meaning that 88 percent of the childbearing decline has been recuperated)

- The permanent decline: $\mathrm{FD}_{\mathrm{c}}=\mathrm{P}_{\mathrm{c}}+\mathrm{R}_{\mathrm{c}}$, which is the absolute difference between the fertility decline at younger ages and fertility rise at higher ages $(=-0.07$ in Diagram 1$)$

For the purposes of this project any decline in fertility of young women is considered a childbearing postponement, and analogously, a fertility increase of older women is considered a childbearing recuperation. "Young women" are of ages 15 to 25 and "older women" of ages 26 to 50; this division was selected because the cohort mean age at birth of the 1944 to 1958 birth cohorts in Russia centered around age 26.

Diagram 1- A simplified scheme of cohort "postponement" and “recuperation”

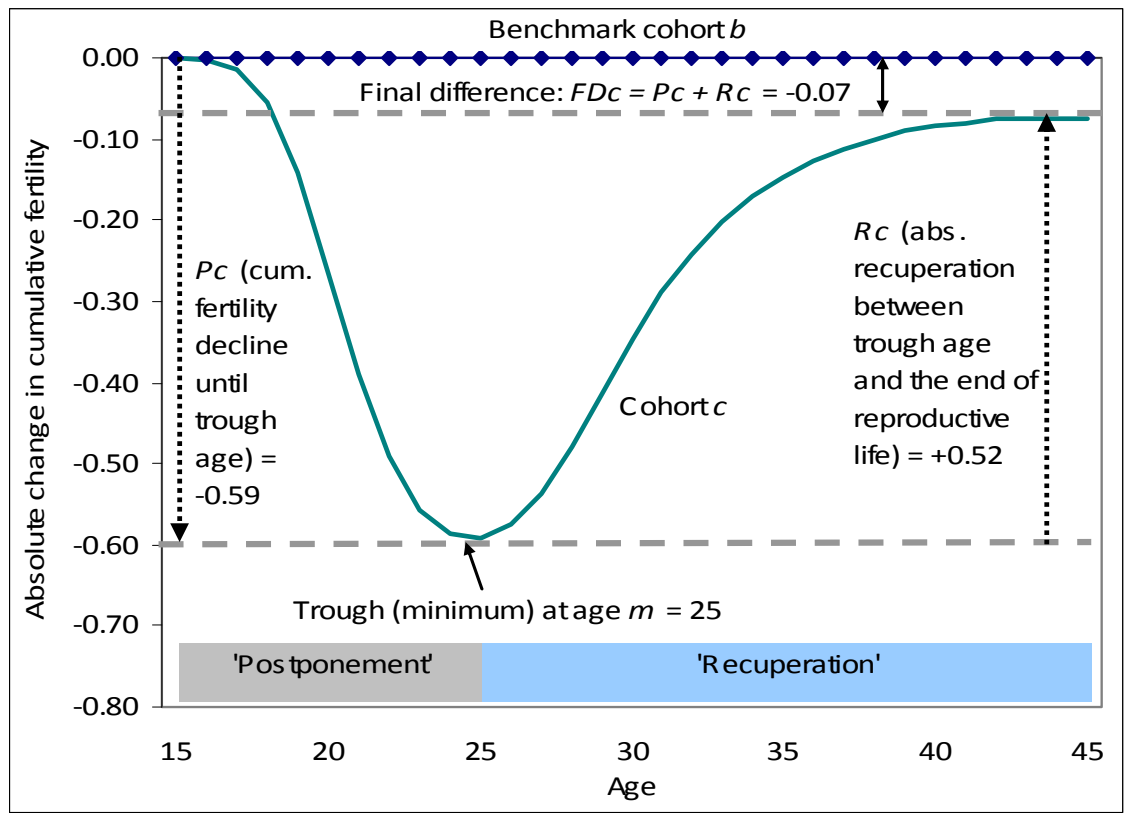




\section{The demographic analysis}

\section{Total period fertility rate trends}

The main overall trends are summarized in Figure 1. Total period fertility rates declined in the 1960s; they stabilized from the late 1960s to the early 1980s; increased during most of the 1980s being stimulated by pro-natalist measures ${ }^{1}$; experienced a steep decline from the late 1980s through the mid-1990s which was undoubtedly associated with turbulent political, social and economic developments; in part the TPFR decline of the 1990s was generated by a modest beginning of childbearing postponement; there was a moderate TPFR decline during 1993-1999 which was a clear phase of fertility postponement; the TPFR increased in 1999-2004 based on childbearing recuperation at older ages 26+; the TPFR increased substantially in 2006-2010 stimulated by the 2007 pro-natalist measures (Figure 1).

\section{Total cohort fertility rate trends (at age 40$)^{2}$ and fertility trends of young and older women}

Between the 1940 and 1960 birth cohorts the TCFR(40) was relatively stable fluctuating in the 1.8-1.9 range (Figures 1 and 2). In contrast to the 1980s TPFRs, TCFRs of the 1950s birth cohorts did not experience any increase that might have been associated with the 1980s pronatalist policy measures. These policy measures basically affected only the timing of births not the overall fertility quantum, the TCFR (40). There was an apparent advancement of childbearing among the late 1950s and early 1960s birth cohorts. The cumulative cohort fertility rates (CCFRs) ages 15-25 increased among the late 1950s cohorts and remained relatively high in the early 1960s birth cohorts (Figure 2). In these same cohorts childbearing was declining among older women 26-40 years old.

Childbearing postponement in Russia started among the cohorts of the mid 1960s. Fertility of young women was falling from these cohorts onward. The 1964 CCFR 15-25 was 1.17 births per woman and declined to 0.70 in the 1982 cohort (Figure 2), the last one for which data were available.

Between the 1960 and 1968 cohorts the TCFR(40) declined from 1.84 to 1.61 births per woman The TCFR decline of the 1960s cohorts was obviously affected by the political, social, and economic developments of the late 1980s and the 1990s. It was these events that triggered the beginning of the childbearing postponement and recuperation process. This process intensified among the 1970s and 1980s cohorts (cf. Figures 3 \& 4).

\footnotetext{
${ }^{1}$ Family policies introduced in the early 1980s included prolonged maternity leaves, options for child-care leave, possibilities of part-time employment for women, extension of earlier measures, such as a one-time child birth benefit graded by birth order, taxes on unmarried men and women, subsidies and privileges for mothers of many children (cf. Zakharov 2008).

${ }^{2}$ The use of cumulated cohort fertility rates by age 40 obviously provides longer time series than using the total cohort fertility rates for the full range of reproductive years ages 15 to 50. Using the TCFRs (40) illustrates virtually identical trends as if TCFRs were used because Russian women had few births after age 40. In the 1940 to 1958 birth cohorts in Russia between 0.8 and 0.4 percent of all births were born after age 40 . In the future later age births may play a larger role because with childbearing postponement fertility is increasing moderately among women in their forties (Sobotka et al. 2007).
} 
Figure 1 - Total cohort fertility rate at age 40 (lagged by 26 years), total period fertility rate, cumulative period fertility rates 15-25 and 26-50, Russian Federation, 1960-2010

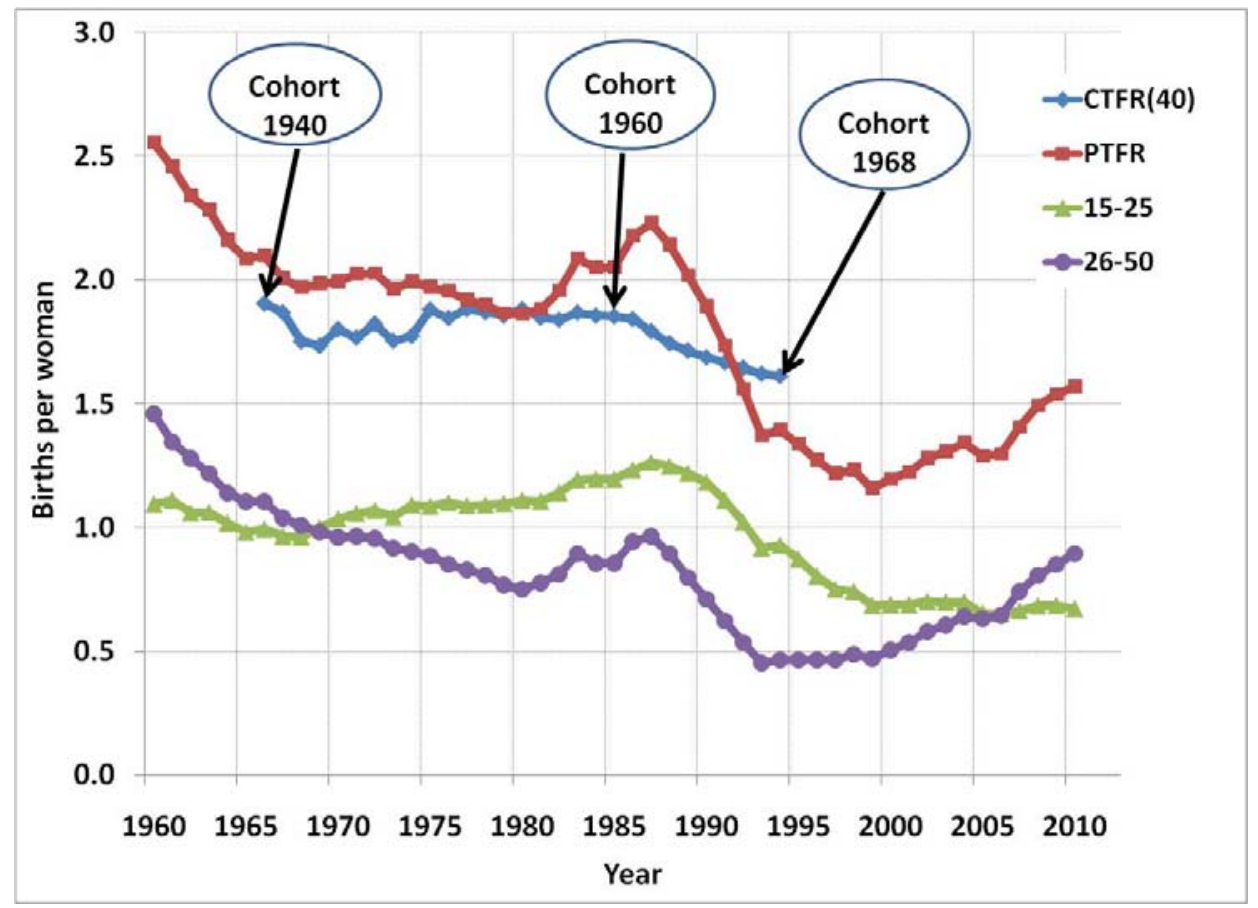

Source: Human Fertility Database 2012

Figure 2 - Total cohort fertility rate at age 40, cumulative cohort fertility rates 15-25 and 26-40, birth cohorts 1940-1982, Russian Federation

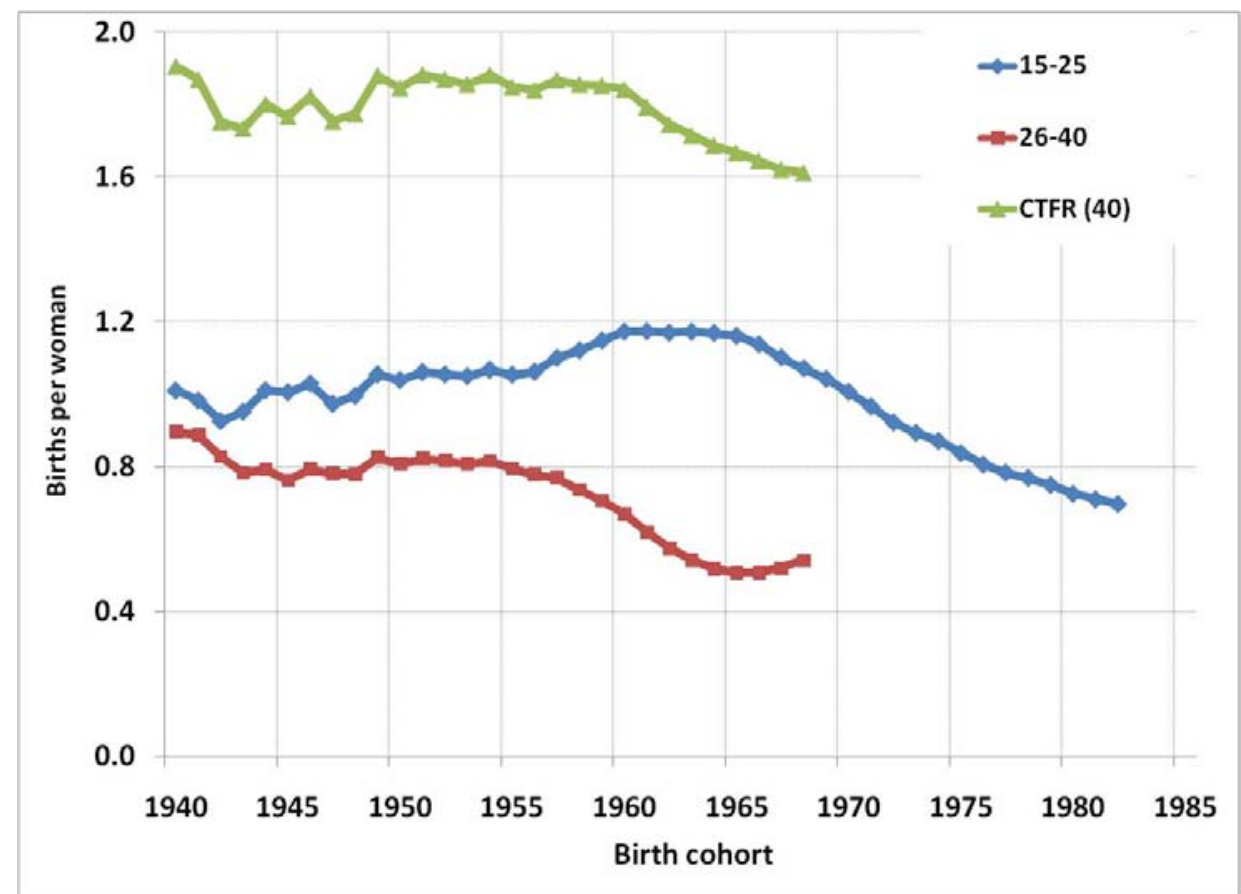

Source: Human Fertility Database 2012 


\section{Cohort childbearing age patterns ${ }^{3}$}

Cohort childbearing age patterns were quite stable among the 1940s and early 1950s birth cohorts. The cohort mean age of birth (CMAB) was around 26.0 years and about 55 percent of births were born below age 26 . The family policies of the 1980s generated a considerable advancement of childbearing. The CMAB (40) declined among the late 1950s and early 1960s cohorts, and reached a low of 24.6 years in the 1965 birth cohort. The percent of births born below age 26 increased to 70 percent in the 1965 cohort (HFD 2011). Among the mid 1960s cohorts the advancement of childbearing turned into childbearing postponement, the CMAB (40) began to increase and the shares of births of young women below age 26 declined. The specifics of these processes can be observed in changing age patterns of fertility (Figures $3 \& 4$ ) and in comparisons of cumulated age-specific fertility rates (Figures 5 \& 6).

Typically, the young age patterns of childbearing of all birth cohorts from the early 1940s to those of the 1970s peaked at ages 20-22 (Figures 3 \& 4).

The fertility advancements of the 1950s birth cohorts are most clearly illustrated in Figure 6. First order births were higher at all ages in the 1960 compared to the 1955 birth cohort (Figure 6, panel B). There was quite an increase in second order births among the cohorts of the early 1950s at all ages, as well as among the late 1950s cohorts especially in women in their late twenties (Figure 6, panel C). Fertility advancements were similar, but on a lower scale among third and higher order births (Figure 6, panel D).

The fertility advancements of the 1950s birth cohorts are most clearly illustrated in Figure 6. First order births were higher at all ages in the 1960 compared to the 1955 birth cohort (Figure 6, panel B). There was quite an increase in second order births among the cohorts of the early 1950s at all ages, as well as among the late 1950s cohorts especially in women in their late twenties (Figure 6, panel C). Fertility advancements were similar, but on a lower scale among third and higher order births (Figure 6, panel D).

The childbearing postponement among the 1960s, 1970s and early 1980s cohorts are illustrated by the fertility declines of young women of all birth orders from one cohort to the next (Figure 4). The magnitude of the fertility decline among young women becomes obvious in the graphs of Figure 5. For instance, women around age 30 in the 1975 cohort had borne almost 0.5 fewer births than in the 1960 cohort (Figure 5, panel A). That a proportion of the births being postponed were being recuperated later in the reproductive ages is illustrated by most of the curves in Figures 5 \& 6 . After reaching a trough, the curves slant upward.

\footnotetext{
${ }^{3}$ Some readers might want to bypass the sections which provide a detailed analysis of fertility trends and patterns (discussion of Figures 5-11 an Table 1) and proceed to section "The childbearing postponement and recuperation $(P \& R)$ process: A synopsis.”.
} 
Figure 3 - Age-specific fertility rates, Russian Federation, birth cohorts 1940, 1945, 1950, 1955 and 1960
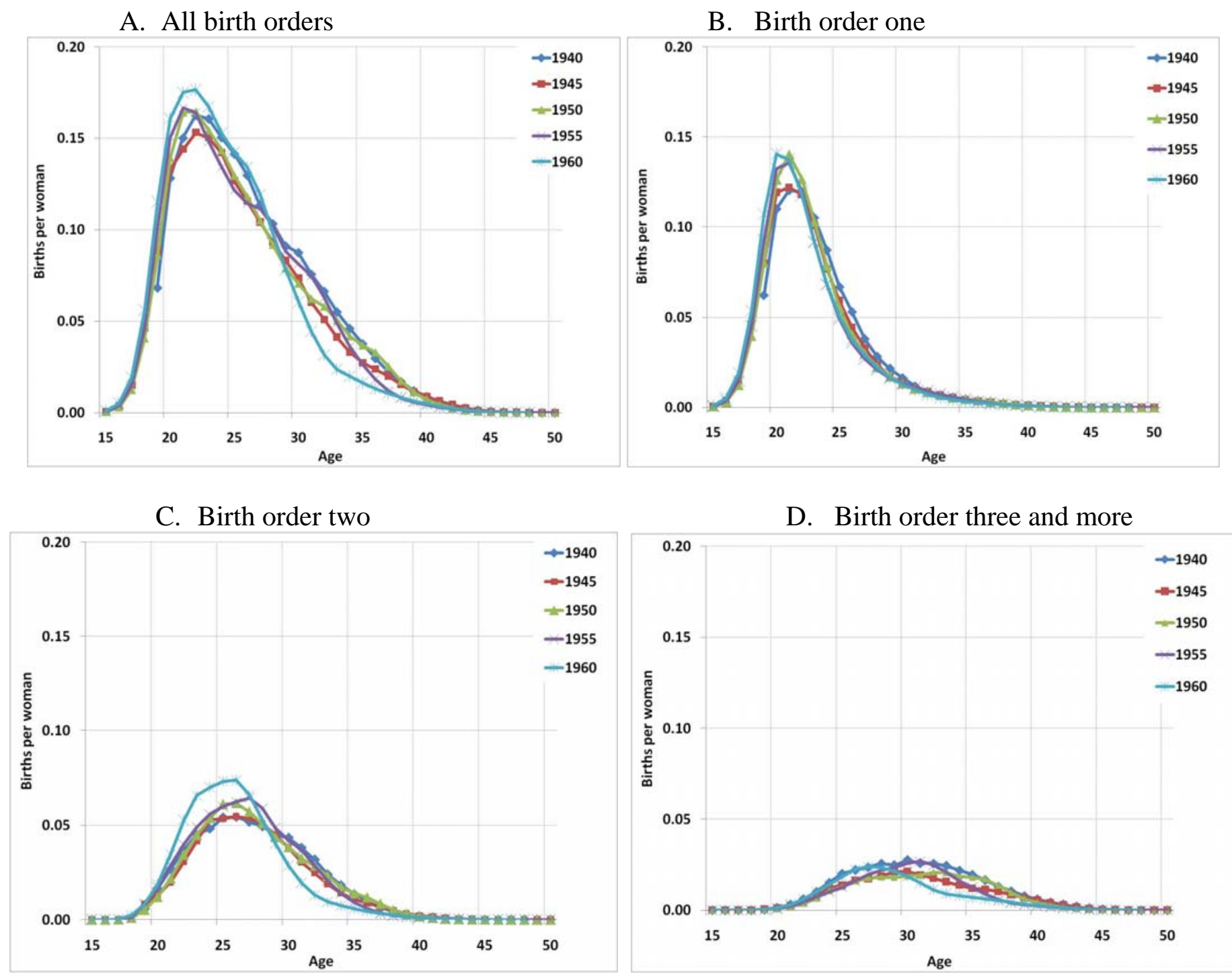

Source: Human Fertility Database 2012 
Figure 4 - Age-specific fertility rates, Russian Federation, birth cohorts 1960, 1965, 1970, 1975, 1980 and 1985

A. All birth orders

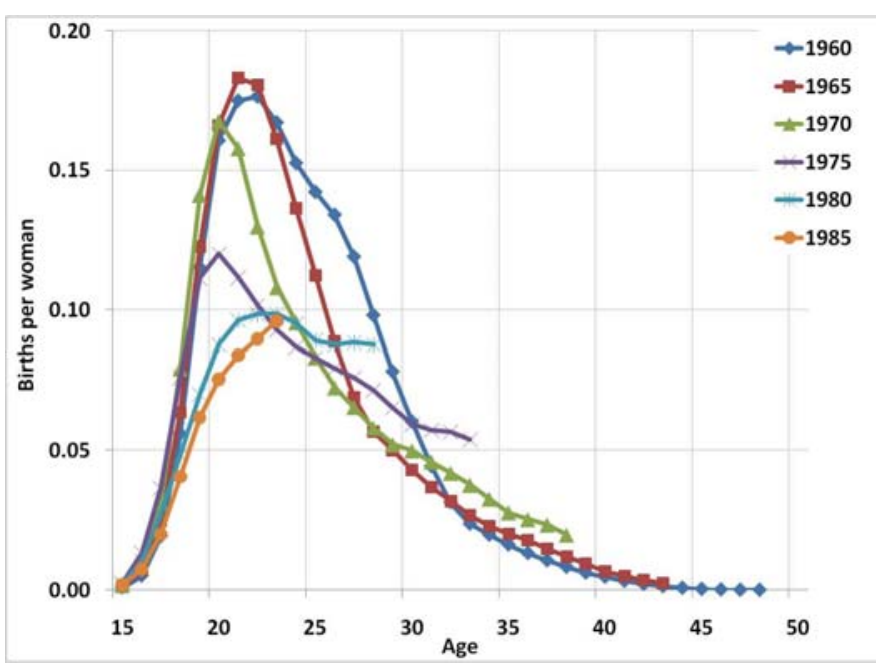

D. Birth order two

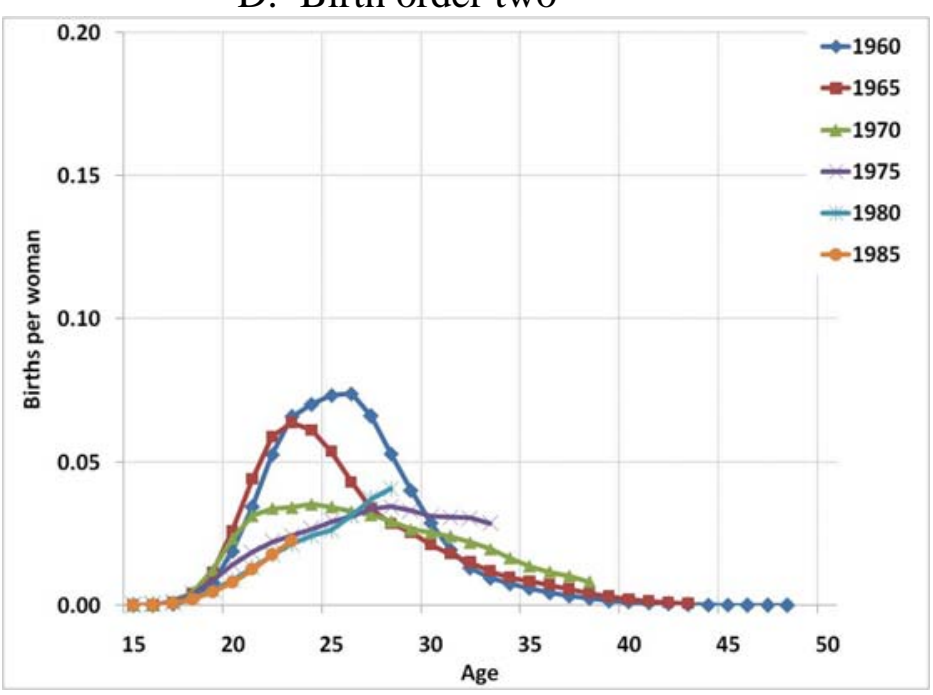

B. Birth order one

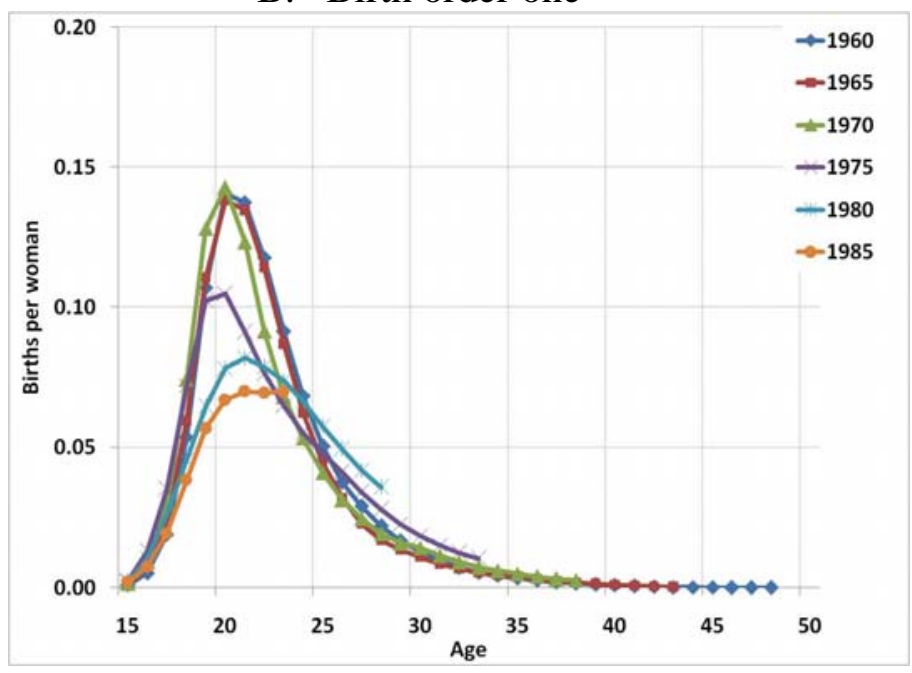

D. Birth order three and more

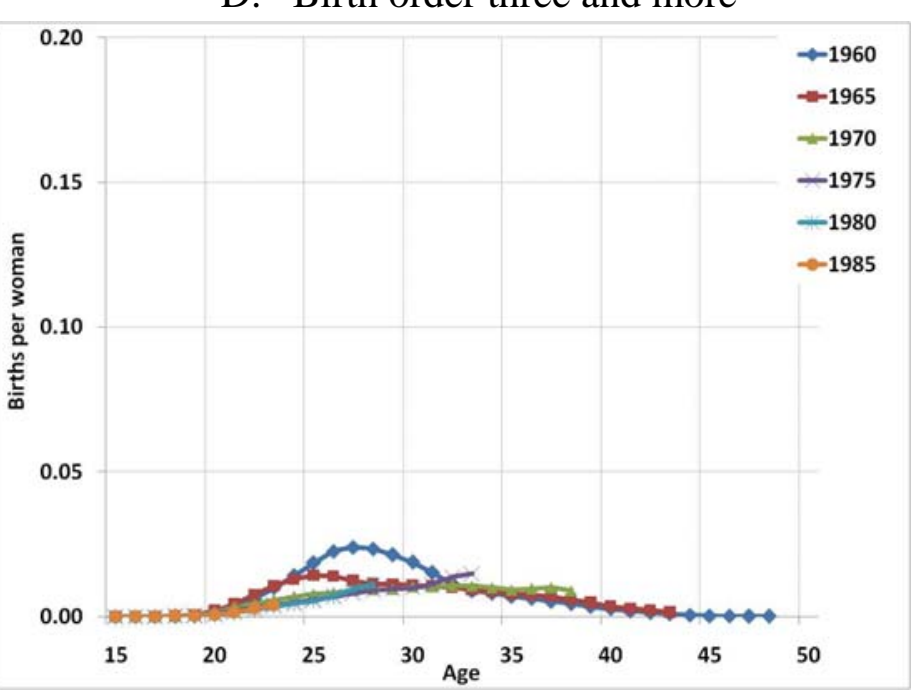

Source: Human Fertility Database 2012 
Figure 5 - Differences in cumulated age-specific cohort fertility rates between base (1960) and subsequent cohorts 1965, 1970, 1975, 1980 and 1985, Russian Federation, by biological birth orders

A. All birth orders

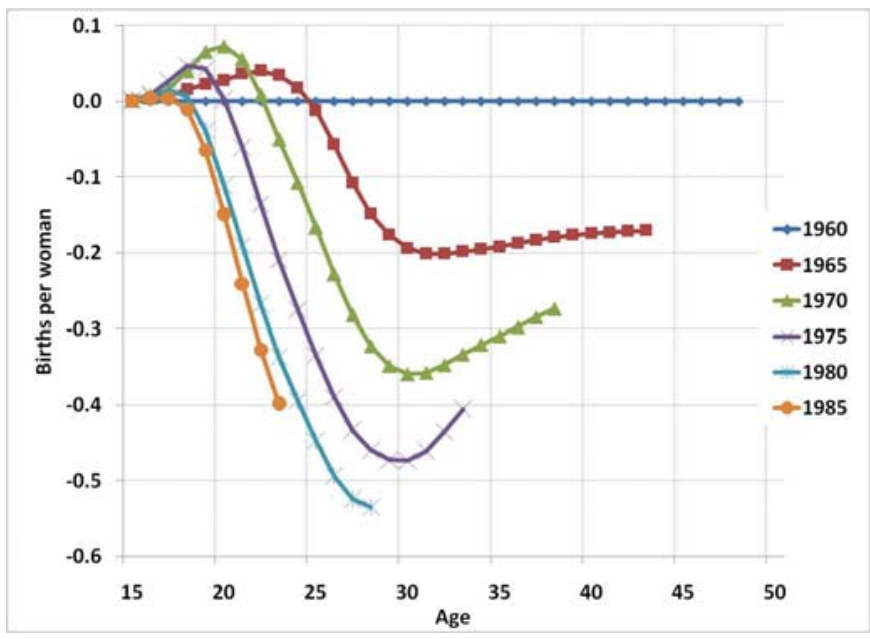

E. Birth order two

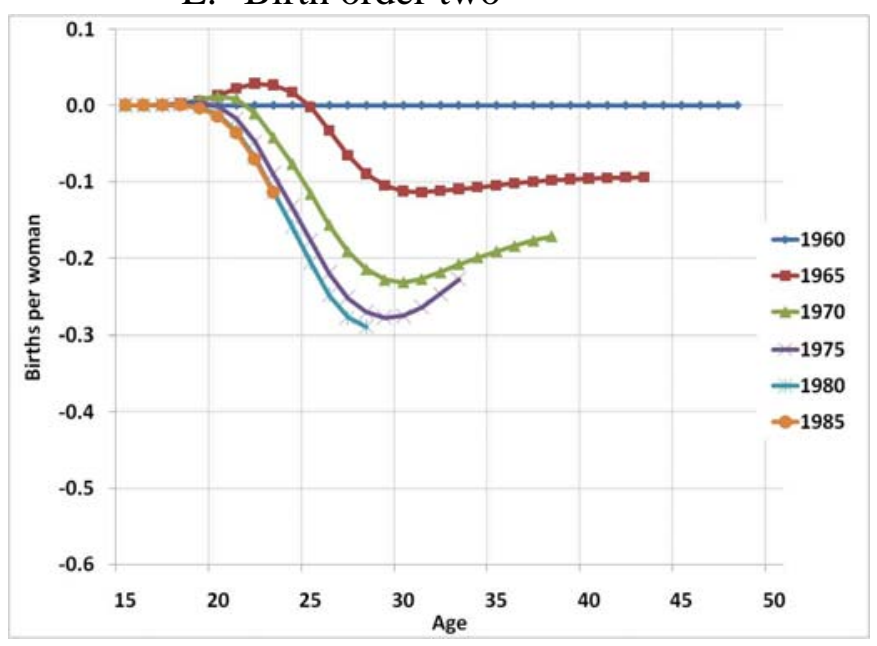

Source: Human Fertility Database 2012
B. Birth order one

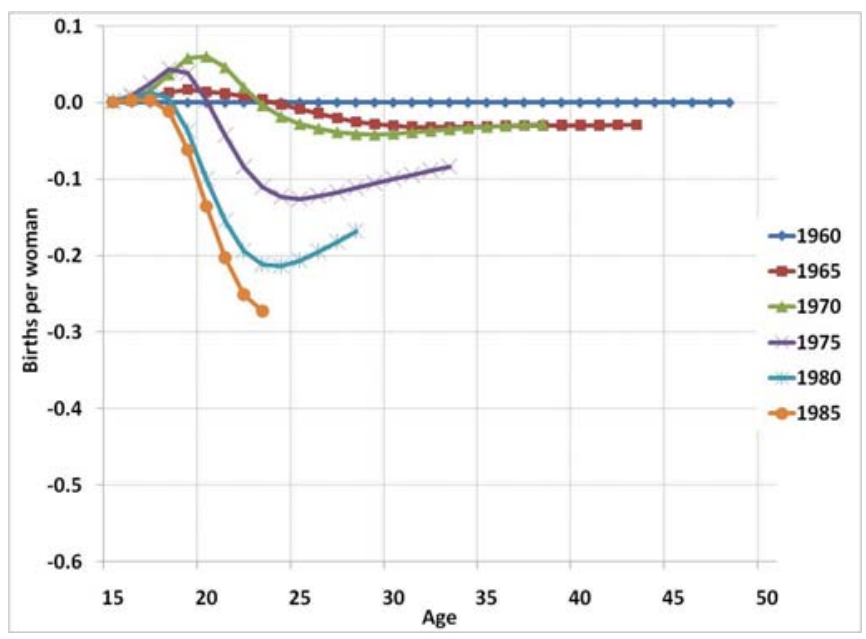

D. Birth order three and more

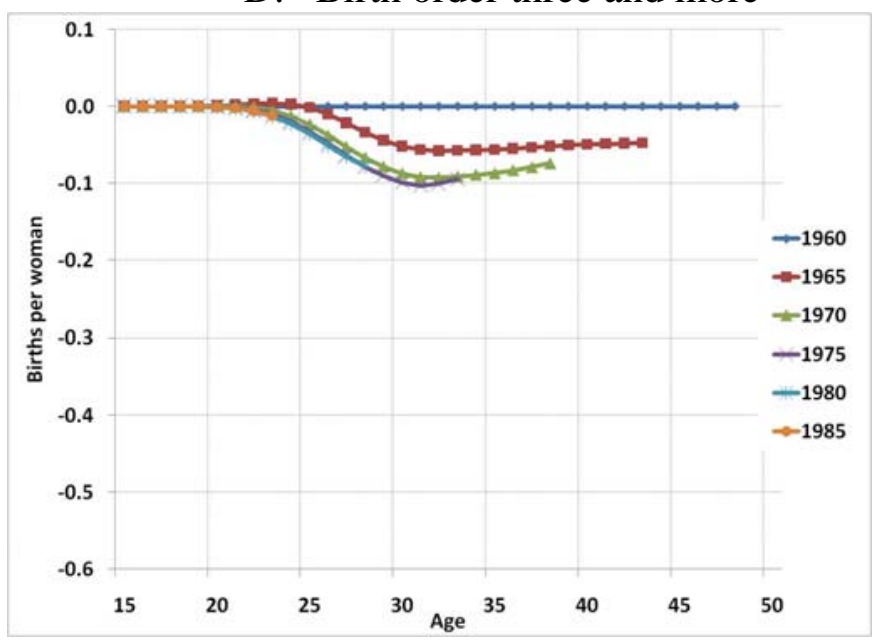


Figure 6 - Differences in cumulated age-specific cohort fertility rates between moving benchmark cohorts 1950-1980 and following cohorts, Russian Federation, by biological birth orders

A. All birth orders

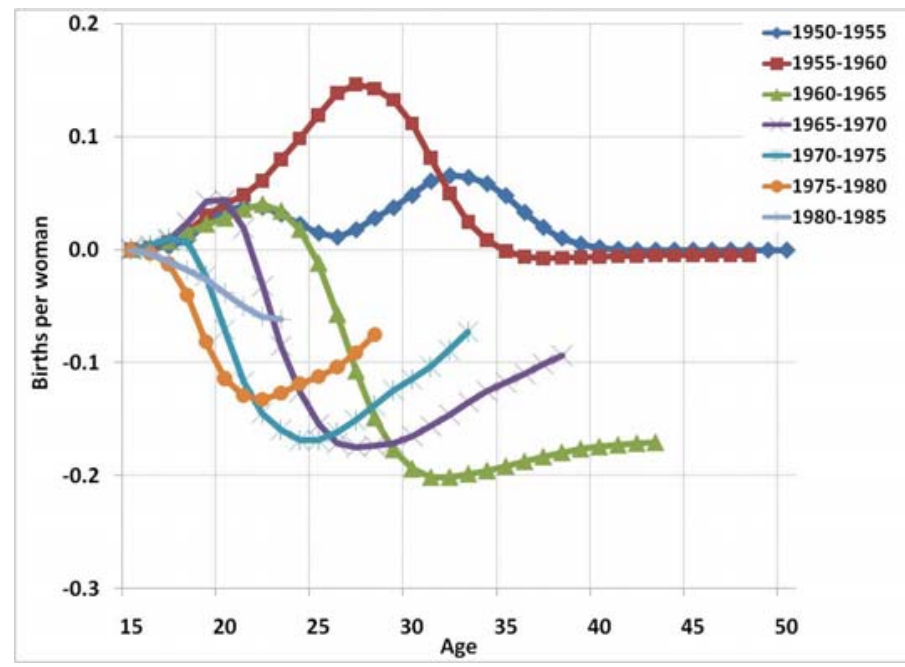

C. Birth order two

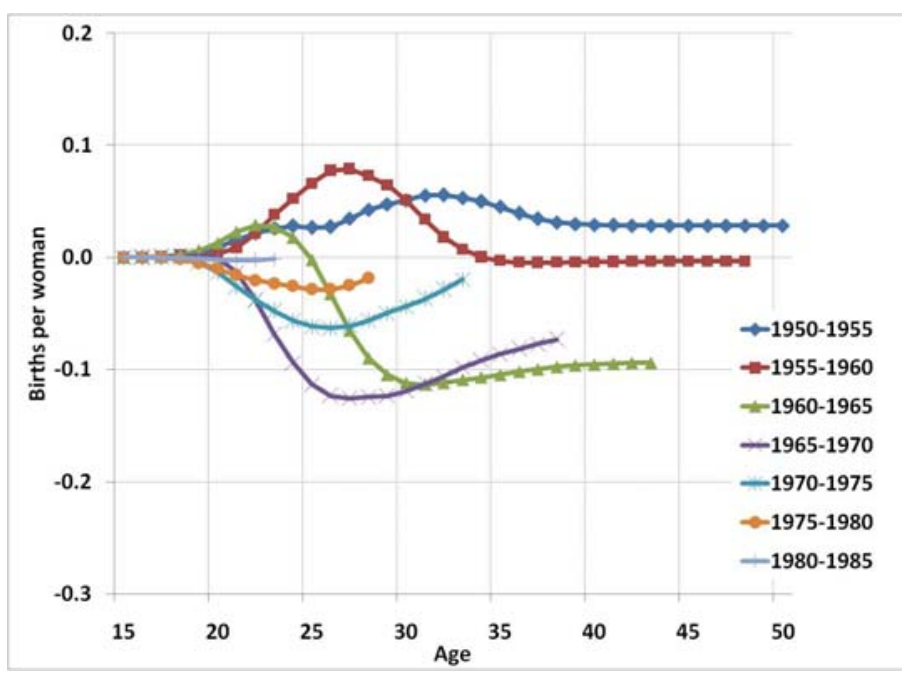

Source: Human Fertility Database 2012
B. Birth order one

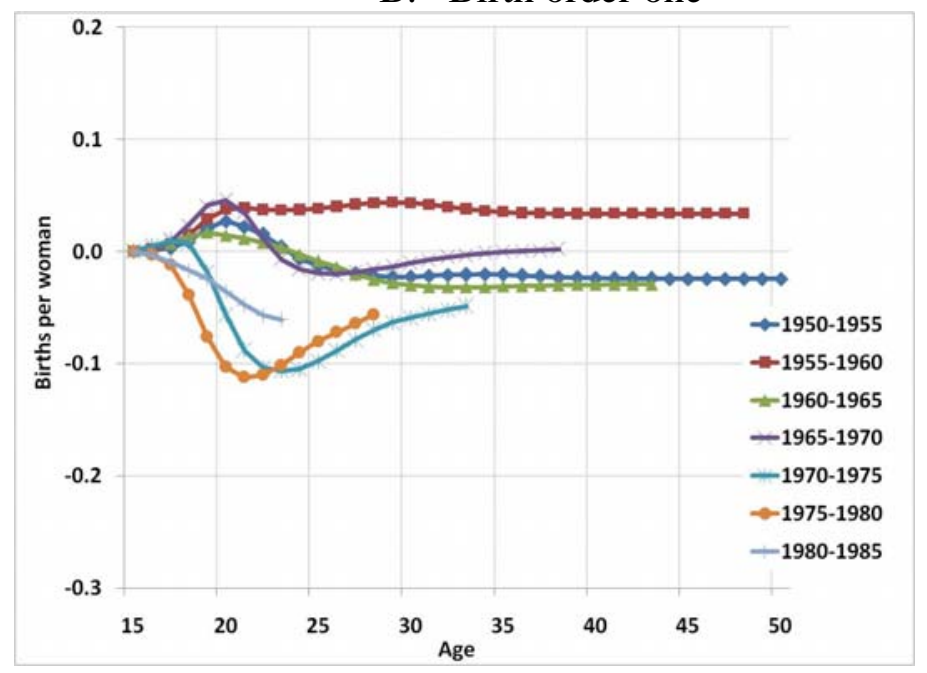

D. Birth order three and more

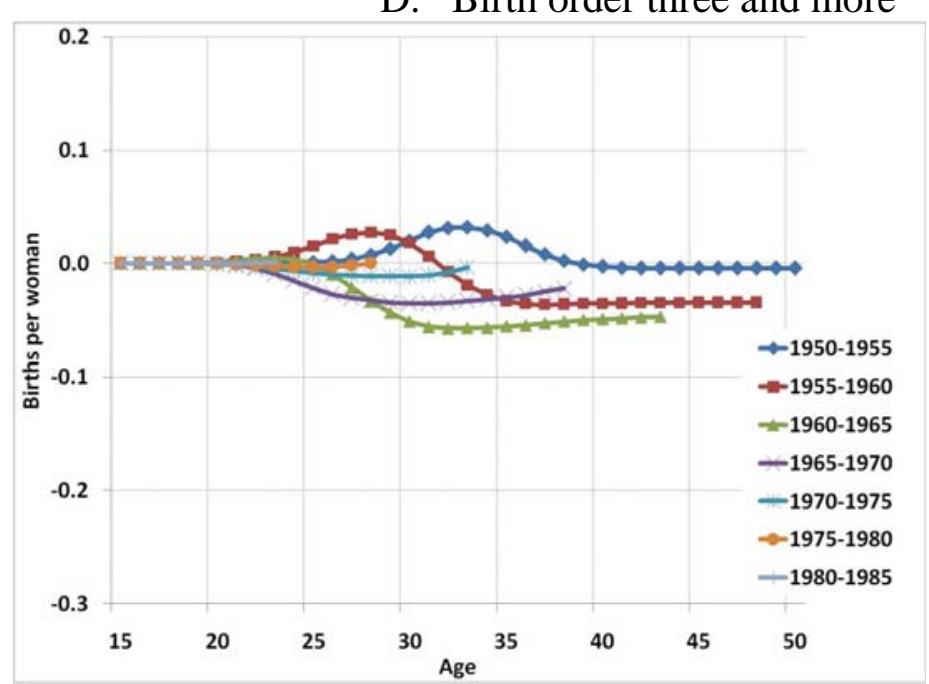


Figure 7 - Differences in cumulated age-specific cohort fertility rates between base (1960) and subsequent cohorts 1970, 1975 and 1980, Russian Federation, by biological birth orders

A. Difference between 1970 and 1960 birth cohorts

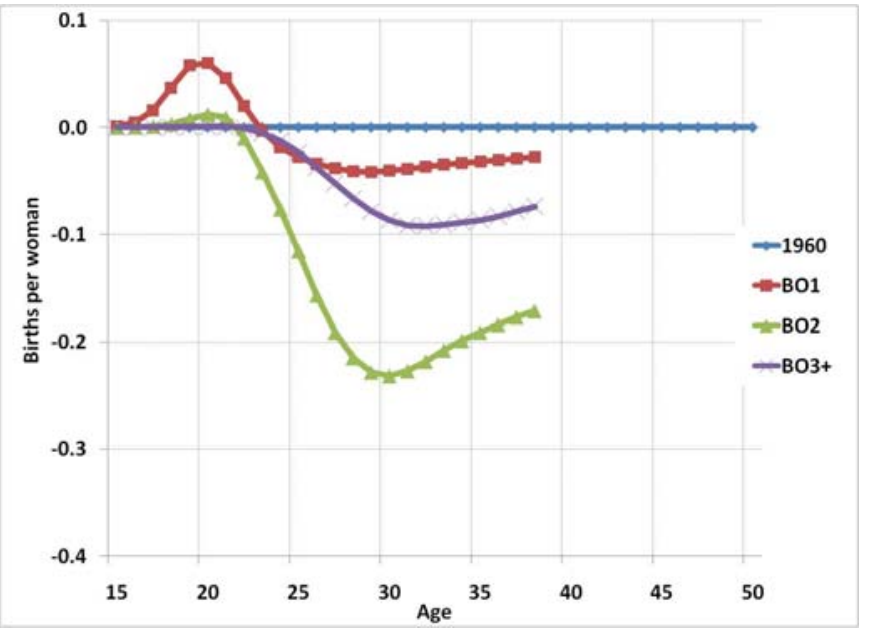

B. Difference between 1975 and 1960 birth cohorts

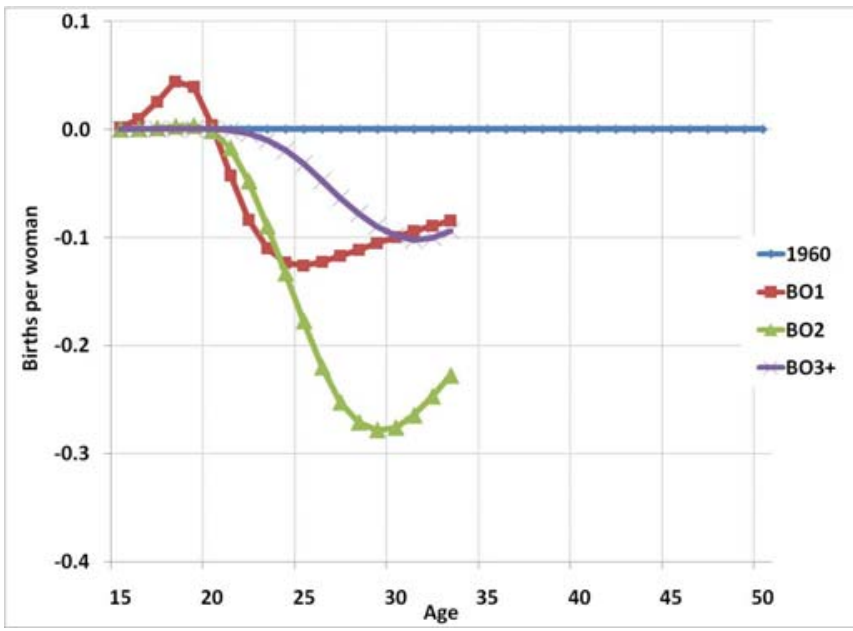

C. Difference between 1980 and 1960 birth cohorts

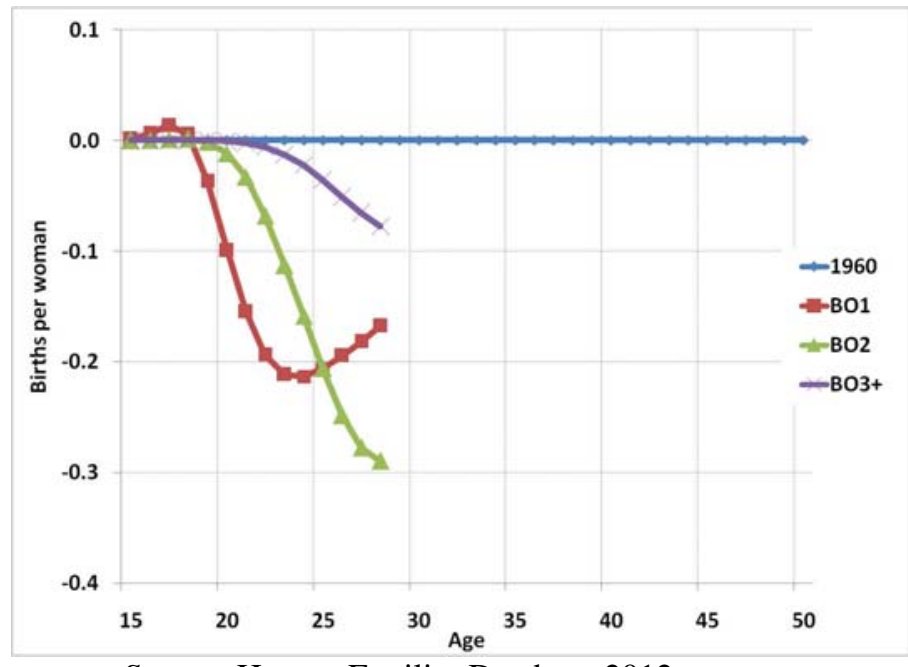

Source: Human Fertility Database 2012 
Figure 8 - Total cohort fertility rates at age 40, by biological birth order, Russian Federation, birth cohorts 1940 to 1968

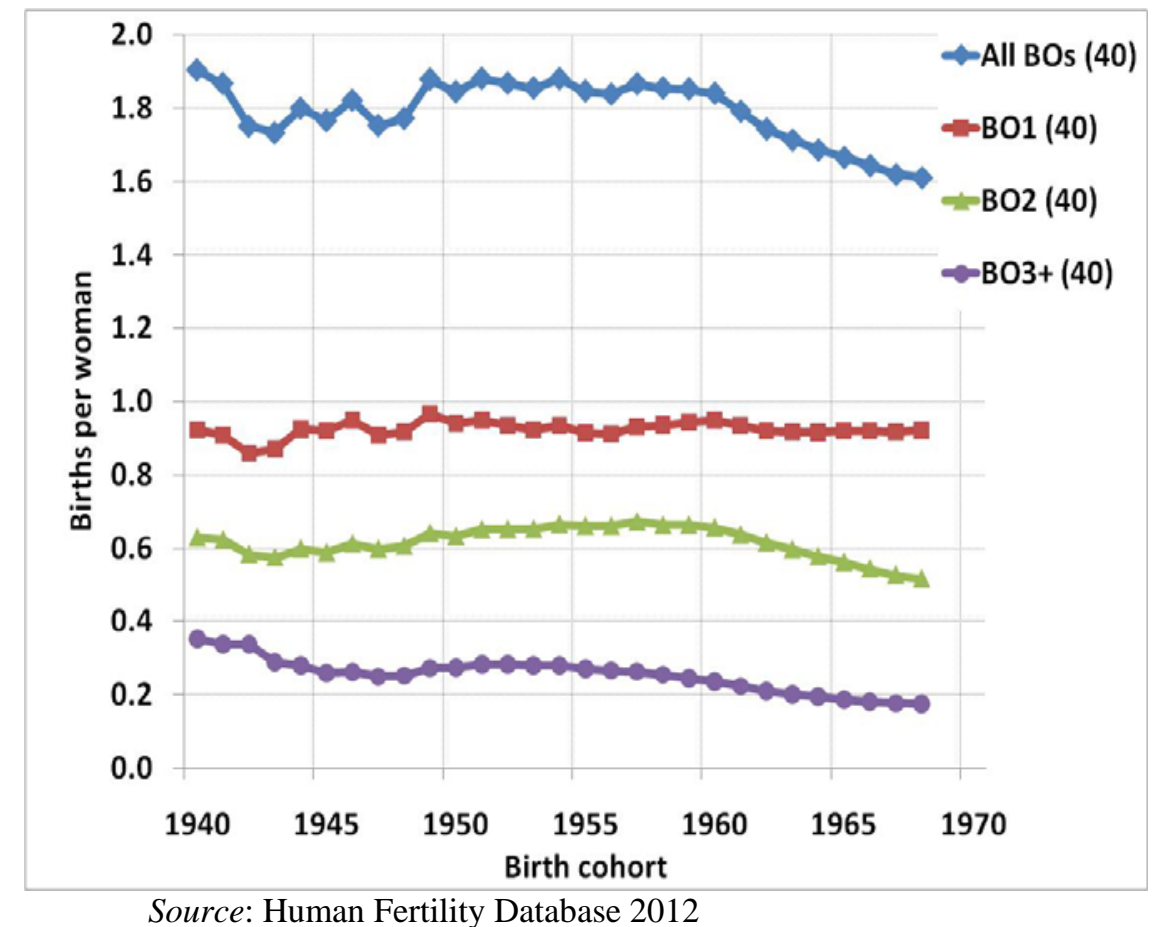

Table 1 - Total cohort fertility rates at age 40, by biological birth order, Russian Federation, birth cohorts 1940, 1950, 1960 and 1968

\begin{tabular}{|c|c|c|c|c|c|c|c|}
\hline & \multicolumn{4}{|c|}{ Birth cohort } & \multirow{2}{*}{$\begin{array}{l}1950 \text { as } \\
\text { percent } \\
\text { of } 1940\end{array}$} & \multirow{2}{*}{$\begin{array}{l}1960 \text { as } \\
\text { percent } \\
\text { of } 1950\end{array}$} & \multirow{2}{*}{$\begin{array}{c}1968 \text { as } \\
\text { percent } \\
\text { of } 1960\end{array}$} \\
\hline & 1940 & 1950 & 1960 & 1968 & & & \\
\hline All BOs (40) & 1.90 & 1.84 & 1.84 & 1.61 & 97 & 100 & 88 \\
\hline BO1 (40) & 0.92 & 0.94 & 0.95 & 0.92 & 102 & 101 & 97 \\
\hline $\mathrm{BO} 2(40)$ & 0.63 & 0.63 & 0.66 & 0.52 & 100 & 104 & 79 \\
\hline $\mathrm{BO}+(40)$ & 0.35 & 0.27 & 0.24 & 0.17 & 78 & 86 & 74 \\
\hline \multicolumn{8}{|c|}{ Shares by birth order (in percent) } \\
\hline All BOs (40) & 100.0 & 100.0 & 100.0 & 100.0 & & & \\
\hline BO1 (40) & 48.4 & 50.8 & 51.5 & 57.1 & & & \\
\hline BO2 (40) & 33.1 & 34.3 & 35.7 & 32.1 & & & \\
\hline $\mathrm{BO} 3+(40)$ & 18.5 & 14.9 & 12.8 & 10.8 & & & \\
\hline
\end{tabular}

Source: Human Fertility Database 2012 
An analysis of the cumulated cohort fertility rates by birth order in Figure 7 illustrates that the main driver of the fertility declines among the 1960s and 1970s birth cohorts was a loss of second order births. This is confirmed by data of total cohort fertility rates by biological birth order. Figure 8 and Table 1 illustrate the roles of birth orders in the overall fertility trends. The considerable decline between the 1960 and 1968 cohorts was mainly due to declines in second and third plus order births. Consequently the weight of first order births increased from 52 to 57 percent of the total.

\section{The dimensions of childbearing postponement}

The overall childbearing postponement for the late 1970s and early 1980s cohorts was about 0.5 of a birth (Figure 9, panel A). The amount of childbearing postponement for first order births was low in the 1960s birth cohorts, but increased among the 1970s and early 1980s cohorts (Figure 9, panels A and B). For second order births childbearing postponement was increasing in the 1960s cohorts, but slowing down in the 1970s cohorts (Figure 9, panels A and B). Childbearing postponement increased for third and higher order births, was not high to begin with and was levelling off among the 1970s cohorts (Figure 9, panels A and B).

Findings of the Gender and Generation Surveys in Russia also illustrate the significance of childbearing postponement. The intervals between the commencement of first unions, cohabitations and marriages, and the date of conception of the first child increased substantially in the 1970-1979 and in the 1980-1989 cohorts compared to earlier birth cohorts (Figure 10).

\section{The dimensions of childbearing recuperation}

It is quite clear that childbearing postponement did not start prior to the 1960s cohorts (see Figures 2, 3, 4 and 5). It follows logically that childbearing recuperation can start to be measured only in the 1960s birth cohorts. By definition the series for which the Recuperation Index can be measured is relatively short because data including at least age 40 are needed. The recuperation index is improving for all birth orders from around 10 percent of postponed births being recuperated to 20 percent (Figure 9, panel D). However, ONLY 20 percent of "postponed” births are being recuperated which is low.

\section{The result of postponement and recuperation for cohorts: The permanent decline at age 40}

The permanent decline at age 40 (Figure 9, panel C) is best understood in conjunction with Figure 8 and Table 1. There was very little permanent decline of first order births because their total fertility rate was relatively steady around 0.92 and was hardly declining among the 1960s cohorts. The permanent decline of second order births was increasing (Figure 9, panel C) as their TFR at age 40 declined from 0.66 births per woman in the 1960 cohort to 0.52 in the 1968 cohort (Figure 8 and Table 1). The permanent decline of third order births was minor because even though their TFRs were declining rapidly, the amount of third+ order births was relatively low between 0.24 and 0.17 births per woman (Figure 8 and Table 1). 
Figure 9 - Major indicators of postponement and recuperation in the Russian Federation by birth order, 1960 benchmark cohort, cohorts born in 1960-1985

A. Absolute cumulative decline at young ages $-\mathrm{P}_{\mathrm{i}}$

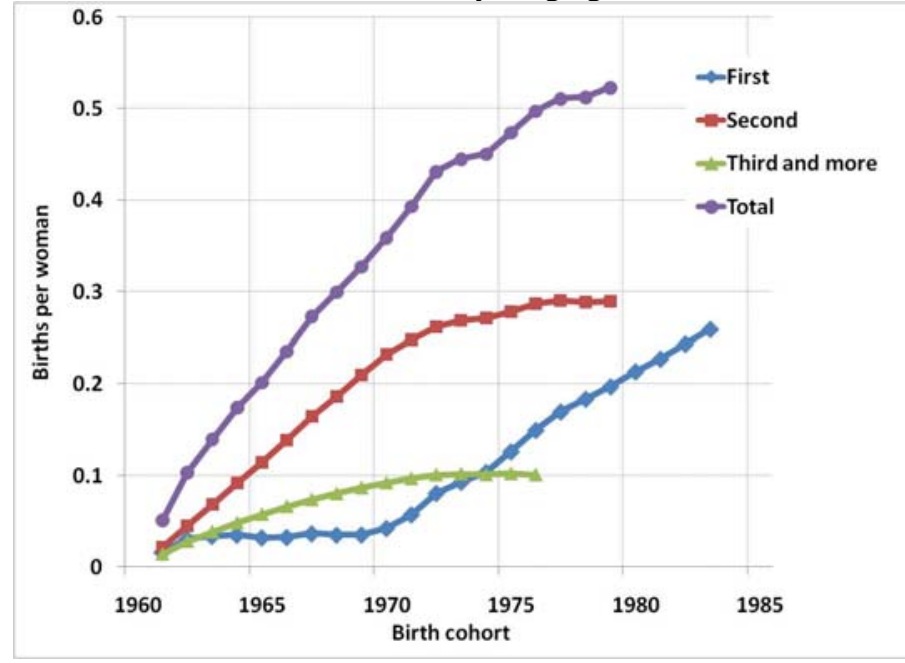

B. Absolute changes in $\mathrm{P}_{\mathrm{i}}$; 3-year moving averages

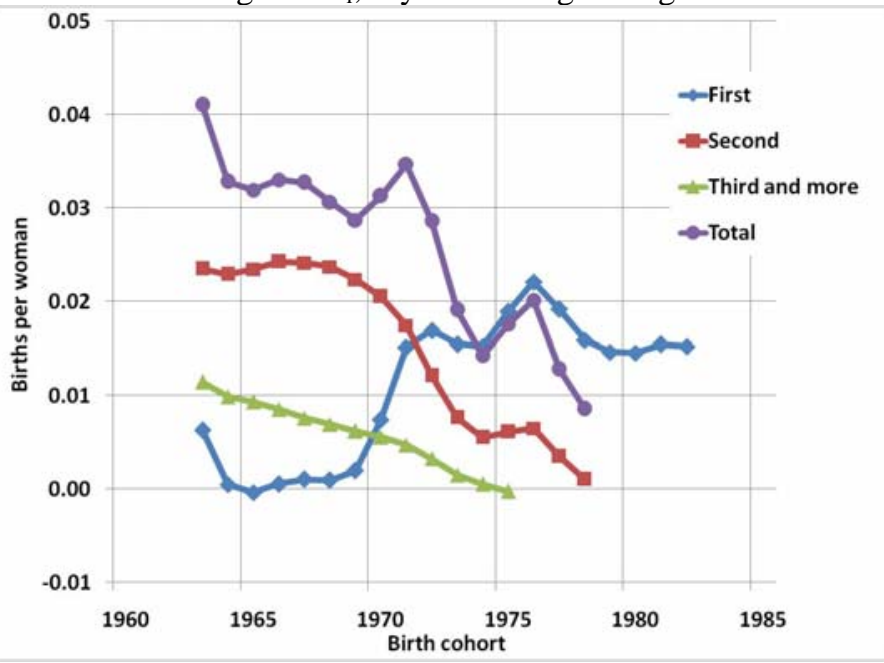

C. Permanent decline in cumulative fertility at age $40-\mathrm{FD}_{\mathrm{i}}$

D. Recuperation Index $-\mathrm{RI}_{\mathrm{i}}$
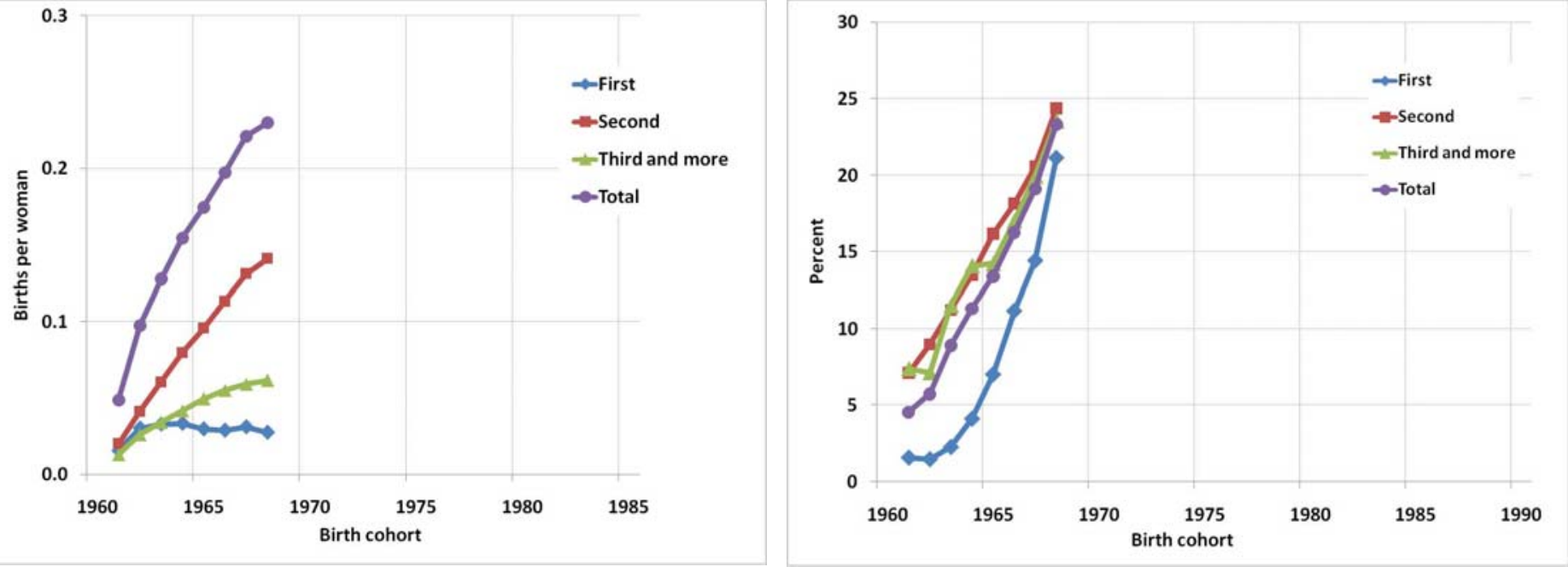

Source: Human Fertility Database 2012 
Figure 10 - Median intervals between the date of commencement of first union, cohabitations and marriages, and the date of conception of the first child (pre-union pregnancies excluded) based on Kaplan-Meier estimators of the cohort survival function, birth cohorts 1920-1929 to 1980-1989, Russia

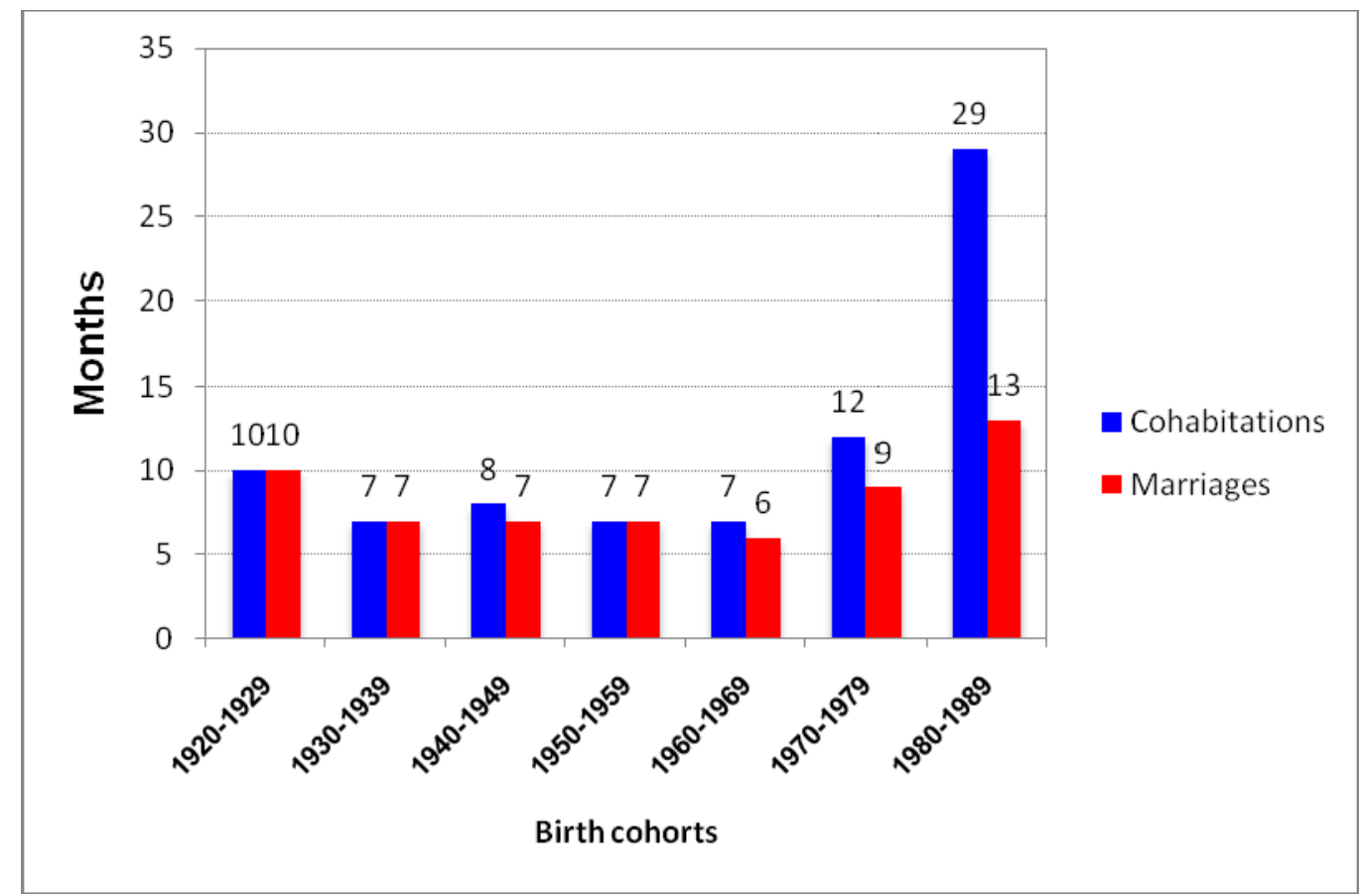

Sources: Mitrofanova 2011, RusGGS-2004, 2007

\section{The childbearing postponement and recuperation (P\&R) process: A synopsis}

The entire preceding analysis is relevant to understanding diverse aspects of the postponement and recuperation process in Russia, but the various detailed analyses can obstruct the view of the overall picture.

The P \& R process began with the mid-1960s birth cohorts in the late 1980s and early 1990s (Figures 1, 2, 4 and 6). It coincided with the steep period fertility decline that started in 1989, and the cohort fertility decline among the 1960s birth cohorts. There were apparently two main factors that caused these fertility declines:

- The wearing off of the effect of the 1980s pro-natalist measures and their gradual discontinuation; and

- The major political, social and economic changes associated at first with "glasnost" as well as "perestroika," and then with the demise of the Soviet Union, which initially led to a deterioration in the living conditions of families with children and eventually to enhanced choices for young people in terms of education, employment, family arrangements and contraception.

To track the $\mathrm{P} \& \mathrm{R}$ process in the cohort perspective only rather short data series are available (Figures 2, 4, 5, 6, 9, 10 and Table 1). Births of young women of all birth orders, especially those 
of birth order two, were declining among the cohorts of the 1960s, the 1970s and the early 1980s. For the time being, in the available brief data series, the recuperation records have been weak (Figures 9 panel D and 10).

In the period perspective, fertility of young women started declining in the late 1980s and continued throughout the 1990s (Figures 1 and 12). At the same time, the fertility decline of older women stopped and in 1994 to 1999 these women experienced a stable fertility trend.

A trough, the lowest point in the TPFR was reached in 1999, 1.16 births per woman. Following the trough the TPFR increased to 1.34 in 2004 and then to 1.57 in 2010 (Figure 1). This period fertility increase was driven solely by a rise in childbearing of older women, those above age 26 . The cumulated fertility rate of young women age 15-25 reached a low of 0.69 births per woman in 1999 and remained at that level throughout the 2000s; it was 0.67 in 2010 (Figure 1 and Figure 11, panel A). The cumulated fertility rate of older women was 0.47 births per woman in 1999 and doubled to 0.90 by 2010. During the period 1999-2004 some of the older women that had previously postponed their births when they were young were recuperating some of these births. A brief plateau in the fertility of older women was reached in 2004-2006. An analysis of the period fertility increases during 1999-2004 illustrate that it was obviously the older women, mainly of the first and second birth orders that were catching up on their childbearing (Figure 11 and Table 2). The fertility rise among older women continued in the late 2000s. One can speculate that some fertility increases among older women would have occurred even without the 2007 family policies, however these policy measures clearly had a considerable impact.

\section{The effects of the 2007 pro-natalist measures: A preliminary analysis}

The policy measures of state assistance to families ${ }^{4}$ were ratified 29-30 December 2006 and went into effect on 1 January 2007. Almost all women were affected by these policies except for young women who had not yet borne any children. In the period 2006-2010 young women were postponing some births as evidenced by a decline in the fertility of first order births (Figure 11 and Table 2). However, the fertility rates of second and third and higher order births of young women did increase (Table 2). It was mainly the older women of all birth orders that apparently took advantage of these pro-natalist measures; their fertility increased from 0.65 births per woman in 2006 to 0.90 in 2010 (Figure 1, Figure 11, panel A and Table 2).

Although it is too early to make an overall evaluation of the impact of the 2007 pronatalist measures, it appears that the effects are wearing off from one year to the next (Figures 1 and 12, Table 3). Taking the differences in the absolute changes from one year to the next for all births (Row 1, Table 3) for each consecutive period the increases in the TPFR were smaller than for the previous period. The TPFR increase for the 2009-2010 period, 0.03 births per woman, was only about a quarter of what it was for the 2006-2007 period, 0.11 births per woman. Similar changes occurred in birth orders (Table 3).

\footnotetext{
4 The "Putin policy" included increases in pregnancy and childbirth benefits, and the introduction of a "maternity capital” that can be used for the child's education, to obtain housing, or to invest in a pension plan (Zakharov 2008).
} 
Figure 11 - Total period fertility rate, Cumulative period fertility rates by age groups 15-25 \& 26-50, Russian Federation, 1990-2010

A. All birth orders

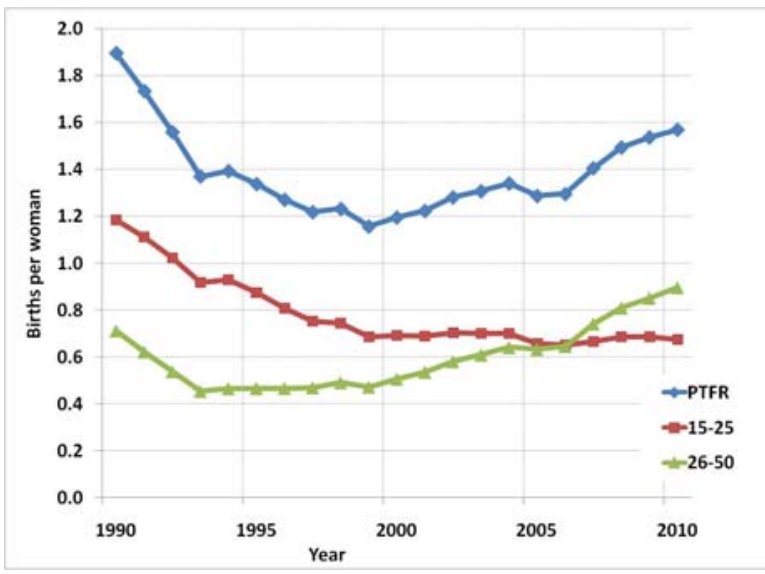

C. Birth order two

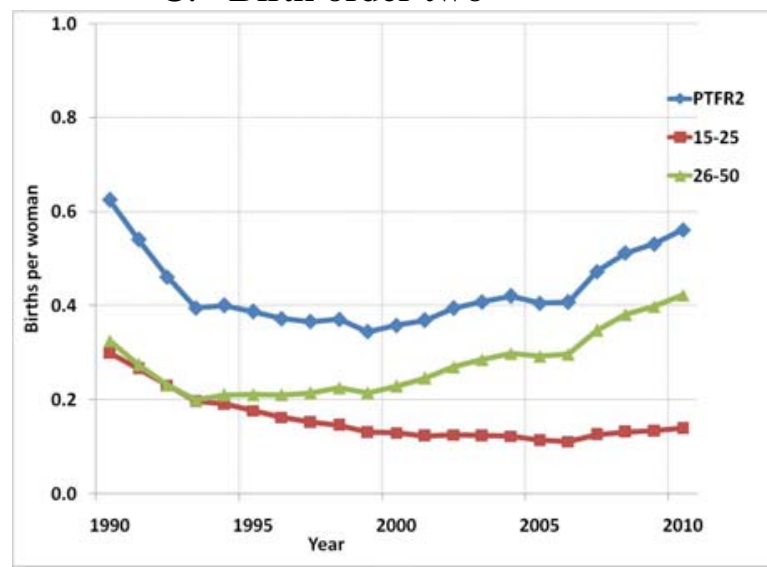

Source: Human Fertility Database 2012
B. Birth order one

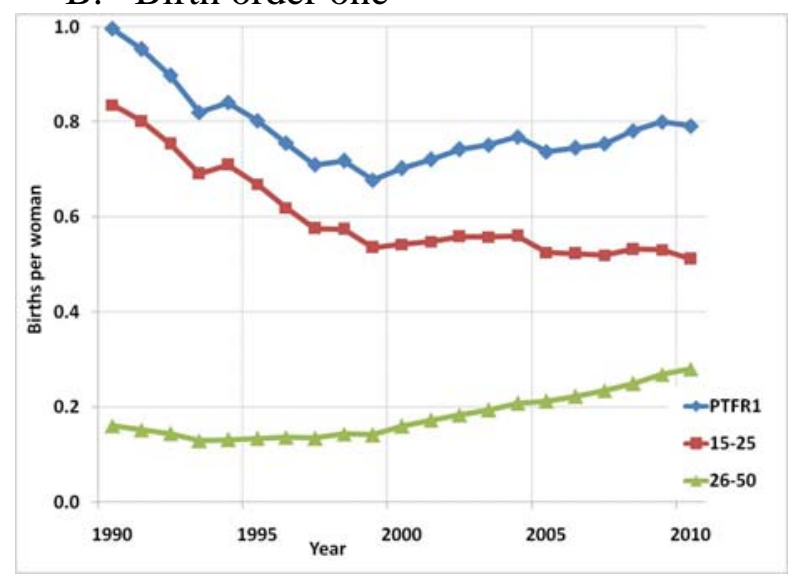

D. Birth order three and more

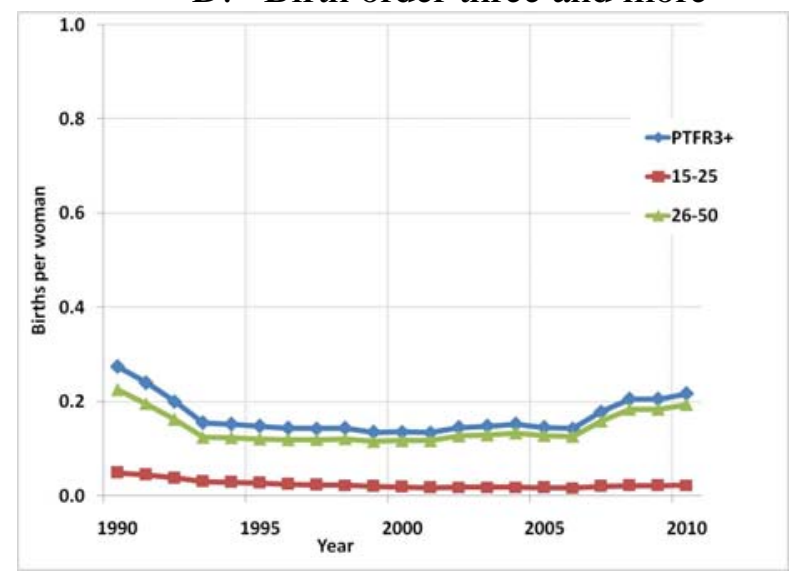


Furthermore, it appears that the family policy measures implemented in 2007 might be having only a limited or no effect on raising the fertility quantum. Despite the fact that financial assistance to families with children was substantially increased and other measures were adopted, intentions to have additional children did not change in the three waves of the Russia Generations and Gender Programme interviews (Table 4). Preliminary estimates based on the GGS 2011 round show that intentions to have another child were virtually the same as in the 2004 or 2007 rounds. Even though the 2007 family policies had been in place for four years, the desires to have an additional child had not changed.

Alternative hypothetical projections reasonably well anchored in contemporary developments indicate that the fertility quantum for the 1970s and 1980s birth cohorts is likely to remain quite stable, even if fertility of the 1970s and 1980s generations were to increase as they age. This provides further evidence that the 2007 family policies might be having only a limited or no effect on raising the fertility quantum. Calculations starting with the numbers of children that were already born by 2011, and assuming that childbearing behavior of older women above age 25 of the cohorts born during the 1970s and 1980s is not going to be much different than that of their elders, indicate that total cohort fertility rates for the 1970s and 1980s cohorts would remain around 1.6 births per woman (Table 5 and Figure 13). If women of the 1970s and 1980s cohorts will bear children with age-specific fertility rates identical to those of women that preceded them at the same age, there will be no change in the TCFRs (Table 5, third numerical column). This assumption is realistic in light of actual trends illustrated in Tables 3 and 4 . At the same time this signifies a considerable recuperation of childbearing in the older ages of the postponed births of these women when they were young (Figure 13). Even if women of the 1970s and 1980s cohorts were to bear children with age-specific fertility rates ten percent higher than women that preceded them, the TCFRs of the 1970s cohorts would still remain at 1.6 births per woman and those of the 1980s cohorts would rise to 1.7 (Table 5 and Figure 13). These are assumptions regarding childbearing behavior of older women in the 1970s and 1980s birth cohorts which might not materialize. 
Table 2 - Total period fertility rate, Cumulative period fertility rates, by birth orders and by age groups 15-25 \& 26-50, Russian Federation, 1999-2010

\section{A. All women}

\begin{tabular}{|c|c|c|c|c|c|}
\hline & \multicolumn{3}{|c|}{ YEAR } & \multirow[b]{2}{*}{$\begin{array}{c}2004-06 \\
\text { average as \% } \\
\text { of } 1999\end{array}$} & \multirow[b]{2}{*}{$\begin{array}{c}2010 \text { as \% of } \\
2004-06 \\
\text { average }\end{array}$} \\
\hline & 1999 & $\begin{array}{c}\text { 2004- } \\
2006 \\
\text { average }\end{array}$ & 2010 & & \\
\hline TPFR & 1.16 & 1.31 & 1.57 & 113 & 120 \\
\hline BO1 & 0.68 & 0.75 & 0.79 & 111 & 106 \\
\hline BO2 & 0.34 & 0.41 & 0.56 & 119 & 137 \\
\hline $\mathrm{BO} 3+$ & 0.14 & 0.15 & 0.22 & 108 & 148 \\
\hline
\end{tabular}

B. Young women ages 15-25 and older women ages 26-50

\begin{tabular}{|c|c|c|c|c|c|}
\hline & \multicolumn{3}{|c|}{ YEAR } & \multirow{2}{*}{$\begin{array}{c}2004-06 \\
\text { average as \% of } \\
1999\end{array}$} & \multirow{2}{*}{$\begin{array}{l}2010 \text { as \% of } \\
2004-06 \\
\text { average }\end{array}$} \\
\hline & 1999 & $\begin{array}{c}\text { 2004-2006 } \\
\text { average }\end{array}$ & 2010 & & \\
\hline \multicolumn{6}{|c|}{ Young women ages $15-25$} \\
\hline All BOs & 0.686 & 0.669 & 0.673 & 97 & 101 \\
\hline BO1 & 0.536 & 0.536 & 0.511 & 100 & 95 \\
\hline BO2 & 0.130 & 0.115 & 0.139 & 89 & 120 \\
\hline $\mathrm{BO} 3+$ & 0.020 & 0.017 & 0.023 & 87 & 131 \\
\hline \multicolumn{6}{|c|}{ Older women ages $26-50$} \\
\hline All BOs & 0.471 & 0.639 & 0.896 & 136 & 140 \\
\hline $\mathrm{BO} 1$ & 0.142 & 0.214 & 0.280 & 151 & 131 \\
\hline BO2 & 0.214 & 0.296 & 0.422 & 138 & 143 \\
\hline $\mathrm{BO} 3+$ & 0.115 & 0.129 & 0.194 & 112 & 150 \\
\hline \multicolumn{6}{|c|}{ Shares by birth order (in percent) } \\
\hline \multicolumn{6}{|c|}{ Young women ages $15-25$} \\
\hline All BOs & 100 & 100 & 100 & & \\
\hline BO1 & 78 & 80 & 76 & & \\
\hline BO2 & 19 & 17 & 21 & & \\
\hline $\mathrm{BO} 3+$ & 3 & 3 & 3 & & \\
\hline \multicolumn{6}{|c|}{ Older women ages 26-50 } \\
\hline All BOs & 100 & 100 & 100 & & \\
\hline BO1 & 30 & 34 & 31 & & \\
\hline BO2 & 46 & 46 & 47 & & \\
\hline $\mathrm{BO} 3+$ & 24 & 20 & 22 & & \\
\hline
\end{tabular}


Table 3 - Absolute changes of period fertility rates, all births, by birth orders and by age groups 15-25 \& 26-50, Russian Federation, 2006-2010

\begin{tabular}{|c|c|c|c|c|c|}
\hline & \multicolumn{5}{|c|}{ Absolute changes of period fertility rates between years } \\
\hline & 2006-2007 & 2007-2008 & 2008-2009 & 2009-2010 & 2006-2010 \\
\hline \multicolumn{6}{|c|}{ All births } \\
\hline PTFR & 0.11 & 0.09 & 0.04 & 0.03 & 0.27 \\
\hline 15-25 & 0.01 & 0.02 & 0.00 & -0.01 & 0.02 \\
\hline 26-50 & 0.10 & 0.07 & 0.04 & 0.05 & 0.25 \\
\hline \multicolumn{6}{|c|}{ First birth order } \\
\hline PTFR1 & 0.01 & 0.03 & 0.02 & -0.01 & 0.05 \\
\hline $15-25$ & 0.00 & 0.01 & 0.00 & -0.02 & -0.01 \\
\hline $26-50$ & 0.01 & 0.01 & 0.02 & 0.01 & 0.06 \\
\hline \multicolumn{6}{|c|}{ Second birth order } \\
\hline PTFR2 & 0.07 & 0.04 & 0.02 & 0.03 & 0.15 \\
\hline $15-25$ & 0.01 & 0.01 & 0.00 & 0.01 & 0.03 \\
\hline $26-50$ & 0.05 & 0.03 & 0.02 & 0.02 & 0.13 \\
\hline \multicolumn{6}{|c|}{ Third and higher birth orders } \\
\hline PTFR3+ & 0.04 & 0.03 & 0.00 & 0.01 & 0.07 \\
\hline $15-25$ & 0.00 & 0.00 & 0.00 & 0.00 & 0.01 \\
\hline $26-50$ & 0.03 & 0.02 & 0.00 & 0.01 & 0.07 \\
\hline
\end{tabular}

Note: col. 2006-2010 might not equal total of preceding columns due to rounding Source: Human Fertility Database 2012

Table 4 - Percentages of respondents aged 25-35 who intend to ever have another child, Generation and Gender Survey, Russian Federation, 2004, 2007 and 2011

\begin{tabular}{cccc}
\hline \multirow{2}{*}{$\begin{array}{c}\text { Parity at the } \\
\text { moment of the } \\
\text { survey }\end{array}$} & GGS-2004 & GGS-2007 & GGS-2011 \\
\cline { 2 - 4 } & 91 & 85 & 88 \\
\hline 0 & 71 & 74 & 71 \\
1 & 29 & 32 & 33 \\
2 & 22 & 30 & 20 \\
3 & 64 & 66 & 67 \\
\hline
\end{tabular}

Source: Author’s calculations based Russia GGS 2004, 2007 and 2011 
Table 5 - Total cohort fertility rates, actual and estimated, five cohort averages based on data available in 2011, Russian Federation, birth cohorts 1955-1959 to 1985-1989

\begin{tabular}{|c|c|c|c|c|c|}
\hline Birth cohort & $\begin{array}{l}\text { Children born } \\
\text { by } 2011\end{array}$ & $\begin{array}{c}\text { Expected } \\
\text { additional } \\
\text { births with } \\
\text { ASFRs at later } \\
\text { ages same as } \\
\text { previous } \\
\text { cohorts at that } \\
\text { age }\end{array}$ & $\begin{array}{c}\text { Actual or } \\
\text { estimated } \\
\text { TCFR }\end{array}$ & $\begin{array}{c}\text { Actual or } \\
\text { estimated } \\
\text { TCFR with } \\
\text { ASFRs at later } \\
\text { ages } 10 \% \\
\text { higher than } \\
\text { previous } \\
\text { cohorts at that } \\
\text { age }\end{array}$ & $\begin{array}{c}\text { Actual or } \\
\text { estimated } \\
\text { TCFR with } \\
\text { ASFRs at later } \\
\text { ages } 10 \% \\
\text { lower than } \\
\text { previous } \\
\text { cohorts at that } \\
\text { age }\end{array}$ \\
\hline 1955-1959 & 1.88 & 0.00 & 1.88 & 1.88 & 1.88 \\
\hline 1960-1964 & 1.76 & 0.00 & 1.76 & 1.76 & 1.76 \\
\hline 1965-1969 & 1.63 & 0.01 & 1.64 & 1.64 & 1.64 \\
\hline 1970-1974 & 1.52 & 0.06 & 1.58 & 1.59 & 1.58 \\
\hline $1975-1979$ & 1.32 & 0.27 & 1.59 & 1.63 & 1.56 \\
\hline 1980-1984 & 0.93 & 0.66 & 1.59 & 1.66 & 1.51 \\
\hline 1985-1989 & 0.44 & 1.14 & 1.58 & 1.70 & 1.45 \\
\hline
\end{tabular}

Source: HFD 2011 and author's calculations

Figure 13 - Total cohort fertility rate at age 40, cumulative cohort fertility rates 15-25 and 26-40, and forecasts, birth cohorts 1940-1982, Russian Federation

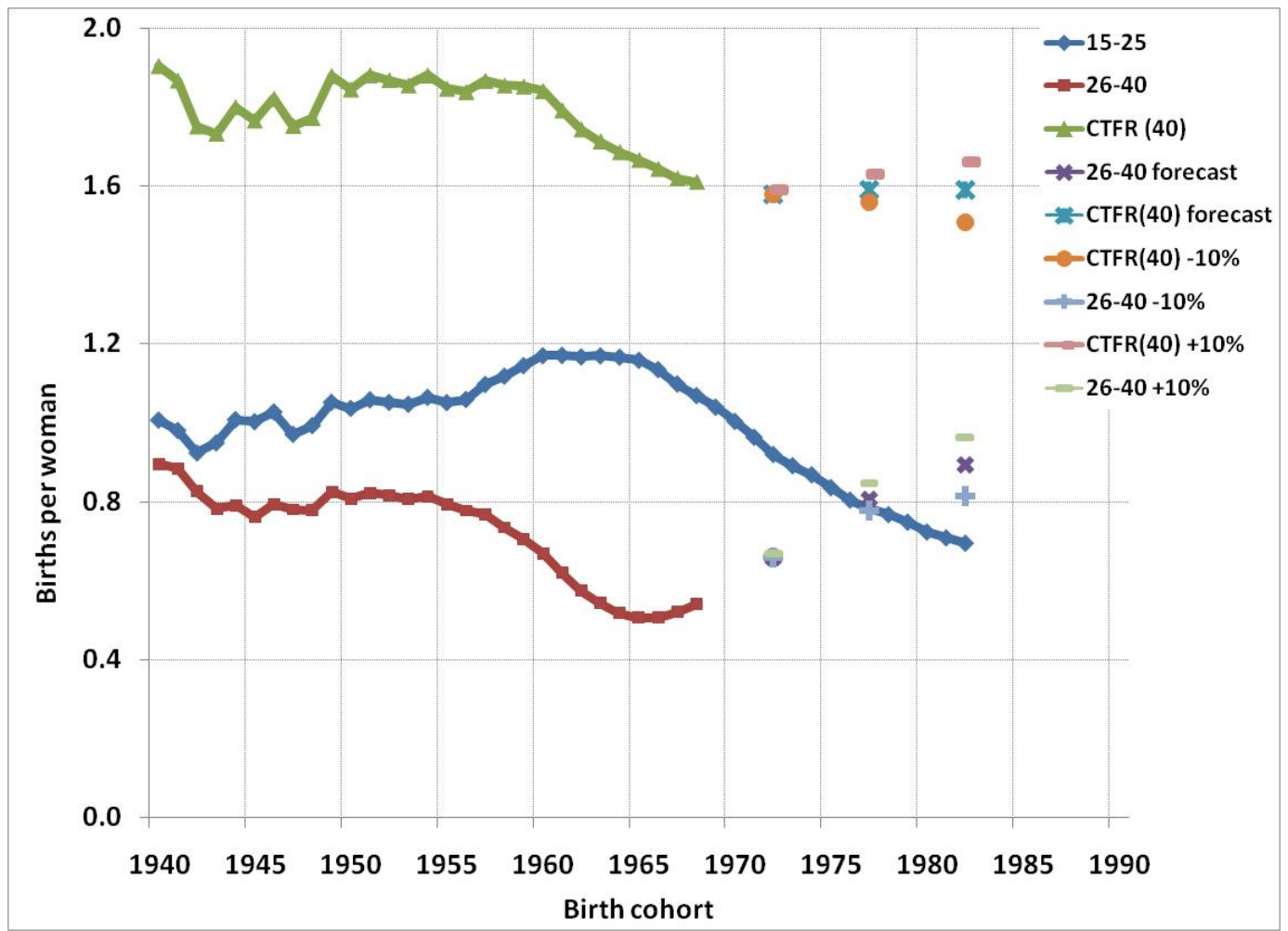

Source: Human Fertility Database 2012, author’s calculations 


\section{Policy reflections}

During the past half century Russia's fertility has been low. Completed cohort fertility of women born during the 1940s and 1950s was around 1.9 births per woman and declined to 1.6 in the late 1960s birth cohorts. The total (period) fertility rate (TFR), the indicator commonly used and perceived as important by policy makers and the general public, declined to 2.0 births per woman, i.e. below the replacement level, in the mid-1960s. Below replacement fertility was firmly established in the European part of the country (Zakharov 2008). The TFR fluctuated around that level through 1980. It increased temporarily during the 1980s, but then descended markedly, and a trough of 1.2 births per woman was reached in 1999 (Figure 1).

\section{A brief evaluation of the early 1980s policy measures}

Social scientists and eventually also the political elite were concerned with the low TPFRs of the late 1960s and 1970s of 1.9 to 2.0. Actual childbearing patterns of early family formation were rooted in the past and "failed to meet the requirements of a modern society whose values include good education, high-quality skills, and high standards of consumption" (Zakharov 2008). Moreover, the labor intensive Soviet economic system required a growing labor force, many non-Russian nationalities had higher fertility than the Russians, and relatively high fertility was considered a positive attribute of socialist societies (Document 1983).

During the 1970s recommendations to address the perceived issues and to increase fertility were discussed in the scientific literature and at professional conferences, and they were gradually embraced by the political leadership. In 1981 the Communist Party Congress adopted a wide range of family and pro-natalist policy measures, such as financial and material assistance to young married couples and families with children, improving housing conditions, increasing the accessibility and quality of preschool establishments, widening the possibilities for part-time employment, work at home for women, and the introduction of partly paid leave to look after small children.

The family policy measures met with a positive response among the population and the period TFR increased from 1.9 births per woman in 1981 to 2.2 in 1987 (Figure 1). Detailed demographic analyses revealed that there was virtually no growth in the quantum of fertility, and that the TPFR growth during the 1980s was generated by an accelerated timing of births. There was no increase in completed fertility of the birth cohorts that were in their prime childbearing ages during the 1980s. During the late 1980s and the 1990s the period TFRs declined as did the TFRs of the 1960s cohorts.

Can one draw the conclusion that the family policy measures implemented during the 1980s failed to accomplish the goal of raising fertility? A simple answer is: Yes, these family policies failed to reach the desired outcome. This conclusion can be disputed by pointing out that societal conditions impacting on fertility behaviour started to change dramatically in the late 1980s and in the 1990s, and that this was the principal reason why the policy measures did not generate any long-term effect. The latter observation can be refuted by the fact that the 1980s advancement of childbearing occurred prior to the changes in the societal conditions of the late 1980s, and if societal conditions had not changed, period fertility and cohort fertility might have stabilized at a 
pre-1981 level. Thus it can be assumed that there would have been no increase in the quantum of fertility and the conclusion that there was no long term effect prevails.

\section{A brief evaluation of the late 2000s policy measures}

The 1990s and the early 2000s witnessed a transformation of marital and reproductive behaviour coupled with a neglect for family policies. As in other low-fertility populations, family formation and childbearing were being gradually postponed, but in comparison to Western countries with a time lag. Government family assistance was negligible. In 1991 family allowances represented 5.6 percent of household income and by 2004 these had dropped 0.4 percent (Zakharov 2008). Fertility declined to unprecedented lows and the size of the population started to shrink, which was due also to high mortality ${ }^{5}$. For over a decade, from 1995 to 2006, the period TFR was at or below 1.3 births per woman. In 1992 Russia's population was at148.4 million and declined to 142.5 million by 2006.

By the mid 2000s the entire demographic landscape became a serious matter of concern. In his May 2006 budget address to the Federal Assembly president Putin highlighted the reduction of mortality, an increase of immigration to Russia, and an increase in the birth rate as principal issues in need of solutions. He placed special emphasis on the necessity to stimulate the birth rate (Zakharov 2008). The following array of policy measures ratified in 2006 came into force in 2007.

- A substantial increase in pregnancy, birth and child benefits progressively graded by child order with the option for regional administrations to authorize additional increases.

- A generously remunerated parental leave (over 2 months prior to birth; about 3 months after birth at 100 percent of annual salary; up to18 months of leave partially remunerated; up to 3 years unpaid leave).

- A new measure, a "maternal capital” initially of 250,000 rubles which was indexed to inflation and grew to 387,640 roubles in 2012 (US\$ 12,000/€9,300 at the April 2012 exchange rate), granted to mothers of second and higher order children which can be used for a child's education, housing, or mother's pension.

An increase of 21 percent in the TPFR from 1.3 births per woman in 2006 to 1.6 in 2010 is evidence of the immediate desired effect of the 2007 family policy measures. The more important question is whether the 2007 family policies will raise the total cohort fertility rates, i.e. the fertility quantum, of the 1970s and 1980s birth cohorts. The evidence summarized below provides the basis for a preliminary answer.

- The impact of the policy measures on period fertility was declining in successive years; in 2007 the TPFR increased by 8.5 percent, but by 2010 it grew only by 2.1 percent (cf. Table 3).

\footnotetext{
51992 was the first year that the number of deaths was higher than the number of births thus generating a negative natural increase, which persisted throughout the 1990s and 2000s. Mortality, especially male mortality increased during the early 1990s and was high through 2006. Male life expectancy at birth was 63.41 years in 1991, declined to 57.38 in 1994 and thereafter increased unevenly to 60.33 years in 2006.
} 
- The desire to have an additional child was the same in 2011 as in the mid 2000s, although the family policy measures had been in force for four years (Table 4).

- Preliminary projections based on children that had already been born by 2011 indicate that TCFRs for women of the 1970s and 1980s cohorts are likely to be virtually the same as those for women of the 1960s birth cohorts (Table 5).

The data and analyses available in early 2012 indicate that any rise in the TCFRs for the 1970s and the early 1980s birth cohorts appears unlikely. This evidence implies that the main demographic impact of the 2007 policy measures has been to advance childbearing thus raising the TPFRs. In other words, women appear to have decided to bear children earlier than they would have without these measures. These conclusions are preliminary because it is impossible to predict the childbearing trends of the next decade. Nonetheless, the preliminary conclusion appears to be that the 2007 policy measures are not likely to raise cohort fertility.

\section{Possible reasons why the policies of the early 1980 s and of the late 2000s did not generate an increase in cohort childbearing}

Based on historical experience with implementing policies to maintain relatively high fertility around the replacement level and the experience with attempting to raise fertility, a consensus has emerged that a broad based comprehensive long-term approach is needed. We shall paraphrase what two prominent demographers wrote on this topic.

McDonald (2002) summarizes what kind of actions should be adopted to increase fertility, and who should be involved in efforts to attain replacement level fertility. While leadership must inevitably come from government, the ideal arrangement is a partnership between government, employers and families in a whole-of-society approach. With respect to what kinds of actions are needed, McDonald lists three categories of fertility policies:

- Financial incentives, such as birth bonuses, child benefits, paid parental leave and tax advantages.

- Support for parents to combine work and family, such as child care facilities, possibility of part-time work and flexible working hours.

- Broad social change supportive of children and parenting, such as promotion of gender equity at home, at work and in all societal institutions.

According to Hoem (2008), the evidence from France and the Nordic countries suggest that it should be possible to maintain a reasonably high ultimate fertility rate by a coordinated use of public policies in a range of interlocking areas (economic policy, employment policy, housing policy, gender policy, core family policy, and more) that are implemented in a spirit that furthers childbearing in general, and do not just consist of making more money available to married families in selected situations. Generous arrangements for parental leave, child benefits, and childcare may be considered desirable in their own right, but such policies alone are unlikely to

succeed in raising the fertility level on a grand scale; they must be embedded in a family-friendly culture deliberately nurtured by the state. Developing such a culture takes time, so any government that wants to increase ultimate fertility needs to realize that it faces a long-term commitment to broadly conceived policies that go far beyond core family policies alone. 
In sum, the operational attributes of a totality of fertility policies likely to have a desired outcome constitute a comprehensive set that is being pursued consistently over an extended period. In very broad terms, it appears that the fundamental reasons why the Soviet policies of the 1980s as well as the Russian policies of the late 2000s did not succeed in raising the quantum of fertility were that they were not sufficiently comprehensive nor were they being pursued for historically extensive time periods. Such a judgement seems justified when evaluating the 1980 policies. As of 2012, it is too early to tell what will be the ultimate result of the policies initiated in 2007. Conceivably these could be expanded or modified, and they might be pursued for many years to come. For the time being, preliminary analyses do not point in the direction of a successful outcome.

\section{Summary and conclusions}

The transformation of traditional childbearing patterns of early family formation to patterns of later family formation with a better educated and more affluent population equipped with skills required by an economically and socially more advanced society was the fundamental feature of the fertility trends of the past half century in Russia. This transformation is embodied in the childbearing postponement and recuperation process which apparently commenced with the birth cohorts of the mid 1960s in the early 1990s and was still in progress around the year 2010. These trends were intrinsically interwoven with fundamental changes in essentially all aspects of life of young people.

The past quarter century was also marked by waves of concern with low fertility and attempts to increase fertility.

When fertility was persistently close to replacement in the 1970s, the Soviet government hoped to remedy this perceived major societal issue by implementing a corpus of pro-natalist policy measures in the early 1980s. Although initially embraced by the population, all that these measures accomplished was to advance childbearing and raise the period fertility rates between 1981 and 1987. But the quantum of fertility remained unchanged among the 1950s birth cohorts, namely the cohorts that were in their prime childbearing ages during the 1980s; their total cohort fertility rates were consistently around 1.9 births per woman.

Fertility resumed its decline during the 1990s with the TPFR at or below 1.3 births per woman from 1995 to 2006. A serious concern about low fertility led to the implementation of an extensive set of pro-natalist measures in 2007 which generated an apparent increase in fertility. The TPFR increased from 1.30 in 2006 to 1.57 in 2010. The annual increase for 2007 was almost nine percent, but this slowed down from year to year. The annual increment of 2010 fertility was two percent. Moreover, preliminary analyses indicate that childbearing was merely being advanced and that the fertility quantum appeared to be retained around 1.6 births per woman.

More than four years are needed to render a conclusive judgement on the outcome of population policies. Birth cohorts primarily affected by the 2007 policy measures, those of the late 1970 s and the 1980s were in the middle of their reproductive years and it is difficult to predict their childbearing in the coming years. Their actual TCFRs, at least around age 40, will not be known until towards the end of the 2010s. It is conceivable that completed childbearing of the 1970s and 
1980s birth cohorts will be higher than preliminary analyses imply, in part due to intensified efforts of governmental and private entities to raise fertility.

As of early 2012, it is obvious that the family policies of the 1980s failed to raise fertility. Preliminary analyses indicate that the fate of the 2007 policies could be similar. There might not be a meaningful fertility increase during the 2010s.

In both cases the main emphasis of the policy sets was on material birth and child benefits, parental leaves and child care. Apparently insufficient attention was devoted to improving general social and economic conditions of young people, such as employment and living conditions, and promoting gender equality at home, at work and in all other societal institutions. The political, social and economic conditions of the 1990s and early 2000s were difficult for the entire population and also clearly affected childbearing. In addition, any pro-natalist policy measures were weakening during that period. The question arises whether the efforts of the government and other entities to raise fertility during the late 2000s and the 2010s will be strong enough and sufficiently effective to offset economic and social forces challenging childbearing. As of 2012 it appears that the outlook for a fertility increase is bleak.

\section{References}

Document 1983. “On Soviet Population Issues (Interview with Timofey Ryabushkin).” Population and Development Review. 9(3):569-572.

Frejka, Tomas 2011. "The role of contemporary childbearing postponement and recuperation in shaping period fertility trends.” Comparative Population Studies - Zeitschrift für Bevölkerungswissenschaft (actual date of publication October 2012).

Hoem, Jan M. 2008. “The impact of public policies on European fertility.” In: Frejka, T., J. Hoem, T. Sobotka and L. Toulemon (eds.), Childbearing Trends and Policies in Europe, Max Planck Institute for Demographic Research, (http://www.demographicresearch.org/special/7): 249-259.

Human Fertility Database. Max Planck Institute for Demographic Research (Germany) and Vienna Institute of Demography (Austria). Available at www.humanfertility.org (data downloaded in March-April 2012).

Gender and Generations Survey, Russian Federation, rounds 2004, 2007 and 2011

Mitrofanova, E. S. 2011. "Demographic Behavior of Russians: Family and Fertility Patterns Across Generations.” The Economic Journal of the Higher School of Economics 15 (4):519-542. (In Russian).http://www.hse.ru/mag/economics/2011-15-4/49834635.html

McDonald, Peter. 2002. "Sustaining fertility through public policy: The range of options," Population (English version) 57(3): 417-446.

Sobotka, Tomáš, Kryštof Zeman, Ron Lesthaeghe and Tomas Frejka. 2011. "Postponement and recuperation in cohort fertility: New analytical and projection methods and their application.” European Demographic Research Papers 2. Vienna: Vienna Institute of Demography.

Sobotka, Tomáš, Hans-Peter Kohler and Francesco Billari. 2007. “The increase in late childbearing in Europe, Japan, and the United States.” Presented at the 2007 Annual Meeting, Population Association of America, 29 March 2007. 
Zakharov, Sergei. 2006. “Age patterns of marriage in Russia.” (in Russian), Otechestvennyie Zapiski No. 4: 271-300.

Zakharov, Sergei 2008. "Russian Federation: From the first to the second demographic transition.” In: Frejka, T., J. Hoem, T. Sobotka and L. Toulemon (eds.), Childbearing Trends and Policies in Europe, Max Planck Institute for Demographic Research, (http://www.demographic-research.org/special/7): 907-972.

\section{Acknowledgement}

The research for this article was in part supported by the Center for Fundamental Studies of the National Research University, Higher School of Economics, Moscow, Russian Federation. 